\title{
El poblamiento andalusí en las tierras de secano: el área sudoriental de La Mancha (ss. XI-XIII)*
}

\author{
The Andalusian Settlement in Dry Lands: South Eastern \\ La Mancha (XI ${ }^{\text {th }}-\mathrm{XIII}^{\text {th }}$ centuries)
}

\author{
Pedro Jiménez Castillo \\ Escuela de Estudios Árabes, CSIC \\ https://orcid.org/0000-0002-6012-4414 \\ José Luis Simón García \\ Universidad de Alicante \\ http://orcid.org/0000-0002-5118-8790
}

Desde los años 80 del pasado siglo, se ha avanzado mucho en el conocimiento del poblamiento rural andalusí vinculado a la agricultura de regadío, tanto en relación a las grandes huertas periurbanas como a los pequeños sistemas hidráulicos de las comunidades campesinas. En las extensas zonas donde escasea el agua, el poblamiento estaría aparentemente concentrado en ciudades y núcleos fortificados ( hușūn $)$, entre los que se extendían secanos deshabitados. Sin embargo, la prospección intensiva de una de estas comarcas, el sector sudoriental de La Mancha, nos está permitiendo documentar un intenso poblamiento rural que responde a un patrón hasta ahora desconocido. Se trata de alquerías (qurā) en llano, carentes de elementos de defensa comu-
Since the 1980s, there has been a significant increase in the number of studies concerning Andalusian rural settlements linked to irrigated agriculture, both related to large suburban green belts and to small hydraulic systems. In the vast areas where water is scarce, the settlement apparently would have been concentrated in cities and fortified towns (hușūn), leaving without population most of the dry lands between them. However, thanks to the intensive survey of one of these regions, La Mancha's Southeastern area, we are recording a dense rural settlement corresponding to a pattern unknown until now. It consists basically of small villages (qurā) in plain, devoid of community defense elements, which must have been inhabited by humble peasants,

* Este trabajo se ha realizado en el marco de un Proyecto I+D, perteneciente al Programa Estatal de Fomento de la Investigación Científica y Técnica de Excelencia, Subprograma Estatal de Generación del Conocimiento, del Ministerio de Economía, Industria y Competitividad, convocatoria de 2015. El proyecto se titula "Almunias del Occidente islámico: arquitectura, arqueología y fuentes documentales" (HAR2015-64605-C2-1-P), ha sido cofinanciado con fondos FEDER y el investigador principal es el Dr. Julio Navarro Palazón (EEA-CSIC).

Copyright: (C) 2017 CSIC. Este es un artículo de acceso abierto distribuido bajo los términos de la licencia de uso y distribución Creative Commons Attribution (CC-by) España 3.0. 
nitarios, que debieron de estar habitadas por campesinos humildes, a juzgar por la modestia de la arquitectura y de los ajuares domésticos. Seguramente explotarían los únicos recursos naturales existentes, que tradicionalmente han orientado la economía de la región hacia la ganadería y la agricultura de secano. De manera particular, el poblamiento estudiado se relacionaría con la demanda de lana para las producciones textiles de la comarca orientadas a la exportación, en el marco de la expansión comercial del periodo. Mayoritariamente estas alquerías parecen haberse desarrollado a partir del siglo XI, desapareciendo a mediados del siglo XIII con motivo de la conquista cristiana. Su existencia estaría asociada a un contexto general de crecimiento demográfico que empujó a la competencia entre las élites urbanas y los campesinos por los espacios agrícolas privilegiados, así como a la colonización de áreas productivas menos favorables.

Palabras clave: Al-Andalus, La Mancha, alquerías, poblamiento rural, agricultura de secano, ganadería, producción textil judging by the modesty of the architecture and domestic goods. Surely they make use of the scanty natural resources, which have traditionally oriented the economy of the region towards livestock and rainfed agriculture. In particular, the studied settlement would be related to the demand of wool for the export-oriented textile production of the region, within the framework of the commercial expansion of that period. Apparently, most of those villages could have appeared in the eleventh century, disappearing in the middle of the thirteenth century because of the Christian conquest. Their existence would be associated with a general context of population growth that pushed the competition between urban elites and peasants pursuing the privileged agricultural areas, as well as the colonization of less favorable production areas.

Key words: Al-Andalus, La Mancha, farmsteads, rural settlement, rainfed agriculture, livestock, textile production.

\section{Introducción}

La reciente investigación sobre la historia social y económica de al-Andalus ha puesto en evidencia el interés fundamental que presenta el estudio del papel desempeñado durante los primeros siglos por los grupos tribales campesinos y su opción por un tipo de agricultura orientada a la autosuficiencia, que no creaba grandes excedentes de productos duraderos y almacenables que fueran fácilmente aprehensibles por parte del Estado o de cualquier tipo de poder ajeno a la comunidad ${ }^{1}$. Al introducirse nuevos cultivos de origen tropical, cuyo crecimiento estival requería abundante riego, además de calor ${ }^{2}$, la agricultura dejó de estar basada casi exclusivamente en la tríada mediterránea (olivo, trigo y vid), que en rigor es la más apropiada a las condiciones naturales de gran parte de la península ibérica. Para ello fue necesaria la cons-

${ }^{1}$ La bibliografía al respecto es muy extensa, así que nos limitaremos a citar algunos textos fundamentales como los de Glick, Irrigation and Society; Bazzana y Guichard, "Irrigation et société"; Barceló et al., Arqueología medieval; Barceló, "El diseño de los espacios"; Barceló, Kirchner y Navarro, El agua que no duerme; Trillo, Agua, tierra y hombres.

${ }^{2}$ Watson, Agricultural Innovation. 
trucción de unos sistemas hidráulicos que aportaran el agua que el clima mediterráneo no proporciona de manera natural, lo que implicaba una utilización intensiva de la tierra y requería un cultivo de gran dedicación. El discernimiento de la estabilidad de los sistemas de irrigación y la lógica que determina su desarrollo han permitido el estudio de estos paisajes históricos como fósiles arqueológicos de la sociedad que los diseñó y utilizó.

Dado su carácter hegemónico, la agricultura de regadío se ha convertido así en un referente determinante a partir del cual entender las otras opciones productivas: la agricultura de secano, la ganadería y las diferentes maneras en que se beneficiaban las zonas incultas, actividades que se han percibido como supeditadas o subalternas a la producción irrigada ${ }^{3}$. De esta manera, durante las últimas décadas se ha venido investigando intensamente en diferentes regiones de lo que fue al-Andalus el desarrollo de los regadíos tras la conquista musulmana y su relación con la implantación de una determinada formación social y sus estrategias económicas. En contraste con estos estudios, existe un notable vacío historiográfico relativo al poblamiento y explotación de las tierras de secano, lo que puede deberse a varias razones. Por un lado, creemos que se dan causas de índole estrictamente metodológica, a saber, la dificultad que entraña el análisis de los espacios productivos medievales mediante las técnicas de la arqueología espacial en ausencia de elementos físicamente identificables en la actualidad como los sistemas hidráulicos. Por otro, y creemos que esta razón ha tenido un peso mayor, porque se ha considerado que el estudio del aprovechamiento económico del secano, explotando en definitiva los mismos recursos naturales que en la Antigüedad, tendría un menor valor desde el punto de vista histórico para el análisis y caracterización de la sociedad andalusí, pues ésta se diferenciaría de la que le precedió en la península ibérica, y también de la feudal con la que coexistió, precisamente por el desarrollo de la agricultura irrigada ${ }^{4}$.

\footnotetext{
${ }^{3}$ Trillo, Agua, tierra y hombres, pp. 53, 54 y 61; Retamero, "Pautes per al l'estudi", p. 32 .

${ }^{4}$ Por ejemplo, Jiménez Puertas y Carvajal López, "Opciones sociotécnicas": "A lo largo del texto dedicaremos relativamente poco espacio al secano y mucho al regadío, lo que puede parecer inapropiado en un encuentro para hablar del primero" (p. 57). La razón se puede resumir en que "podemos concebir la opción del regadío [andalusí] como opuesta a la opción de secano existente en la sociedad tardoantigua..." (p. 74).
} 
En este contexto general de penuria historiográfica, cabe destacar los estudios relativos a las áreas de secano que formaban parte de los espacios agrícolas de las alquerías y que pudieron establecerse al mismo tiempo que las parcelas irrigadas, durante el proceso de construcción del sistema hidráulico ${ }^{5}$. Aún más excepcionales son los estudios que se ocupan estrictamente del aprovechamiento y poblamiento del campo; es decir, el espacio de secano en el que las huertas son inexistentes o irrelevantes en el conjunto de la economía campesina ${ }^{6}$. De igual manera, apenas tenemos información acerca de la ganadería en al-Andalus, por razones análogas a lo que sucede con la agricultura de secano, y lo poco que sabemos corresponde mayoritariamente a época nazarí, es decir, a un momento tardío ${ }^{7}$. Este precario estado de la investigación es, precisamente, una de las razones que avalan el interés del presente trabajo, pues tenemos intención de examinar una amplia comarca cuyas condiciones geográficas no permitían la existencia del regadío más que de forma testimonial. Está situada en el sector sudoriental de La Mancha, en la actual provincia de Albacete, que en época andalusí constituía el iqlìm o territorio dependiente de la madìna de Chinchilla. En este limitado espacio hemos podido documentar decenas de alquerías, por lo que parece que el desierto de asentamientos andalusíes en el secano es más historiográfico que histórico. Sin embargo, no se puede poner en duda que el regadío, que minimiza los riesgos derivados de la meteorología, era la opción campesina preferente, mientras que la colonización y explotación del secano era una alternativa aventurada que comportaba peligros y escasa rentabilidad, al igual que la ganadería que en la etapa preindustrial registraba siempre altas mortandades por la amenaza constante de las epidemias ${ }^{8}$.

Las prospecciones sistemáticas de campo nos han permitido localizar una serie de yacimientos cuyo estado de conservación permite en

${ }^{5}$ Trillo, Agua, tierra y hombres, pp. 208-219; Kirchner, "Redes de asentamientos", pp. 85 y 86 .

${ }^{6}$ Sabaté y Brufal, Els espais de secà. Entre los escasos precedentes cabe destacar los estudios de Jesús Brufal relativos a los asentamientos andalusíes del Pla de Lérida, que estaban asociados de manera casi exclusiva a cultivos de secano y a la ganadería (Brufal, "La Lleida de secano").

${ }^{7}$ Podemos destacar: Cara, "Huellas de pastores"; Malpica, "La vida agrícola y la ganadería"; García-García y Moreno-García, "De huertas y rebaños". En estas publicaciones queda recogida el resto de la bibliografía sobre el tema.

${ }^{8}$ Newfield, "Early Medieval Epizootics", p. 77. 
muchos casos levantar planimetrías generales en las que se pueden registrar los perímetros de manzanas y edificios e, incluso, a veces la distribución interna de estos últimos ${ }^{9}$. El objetivo del presente estudio no es sólo efectuar una relación y descripción de dichos asentamientos, sino analizarlos como una parte del registro arqueológico para el estudio histórico de la economía y sociedad del territorio, en un contexto que, en general, parece que podría interpretarse como la colonización de espacios marginales y pobres, asociada a un proceso de comercialización intenso en al-Andalus durante la fase central de la Edad Media.

\section{El territorio}

El territorio de la actual provincia de Albacete está inscrito en la región sudoriental de la Meseta Ibérica, en el borde marginal del zócalo meseteño. Se divide a grandes rasgos en cinco extensas comarcas naturales: el Campo de Hellín, la Sierra de Segura, los Llanos de Albacete, las tierras de Montearagón y el Valle del Júcar y el Cabriel (fig. 1). Dentro de estos ámbitos se dan espacios con una singularidad manifiesta, como la cuenca del río Mundo, las tierras de Alcaraz, las Lagunas de Ruidera, La Manchuela, el Corredor de Almansa o las tierras de Caudete ${ }^{10}$. Sus peculiaridades son determinantes en el tipo de poblamiento, antecedentes históricos y culturales, contactos e influencias con otras zonas y, sobre todo, en su adscripción a los diferentes ámbitos políticos que a lo largo del periodo islámico se sucedieron en el tiempo.

El sector oriental, en el cual se agrupan las tierras que en la Edad Media dependían de Chinchilla, se caracteriza por ser un espacio de transición entre las comarcas interiores del Šarq al-Andalus y los llanos de Albacete en La Mancha oriental. Se trata de un ámbito delimitado en su flanco oriental por las últimas estribaciones surorientales del Sistema Ibérico y las nororientales del Prebético, entre las que se abre un paso, el Puerto de Almansa, algo más directo que el de Los Alhorines, entre Fuente la Higuera y Caudete, camino tradicional por donde transcurrió la vía Heraclea o Augusta, un espacio de tránsito entre el Levante

\footnotetext{
${ }^{9}$ Las cartografías que aquí presentamos han sido elaboradas por D. Ignacio Segura, de Tossal Topografía, S. L.

${ }^{10}$ Sánchez, Geografía.
} 


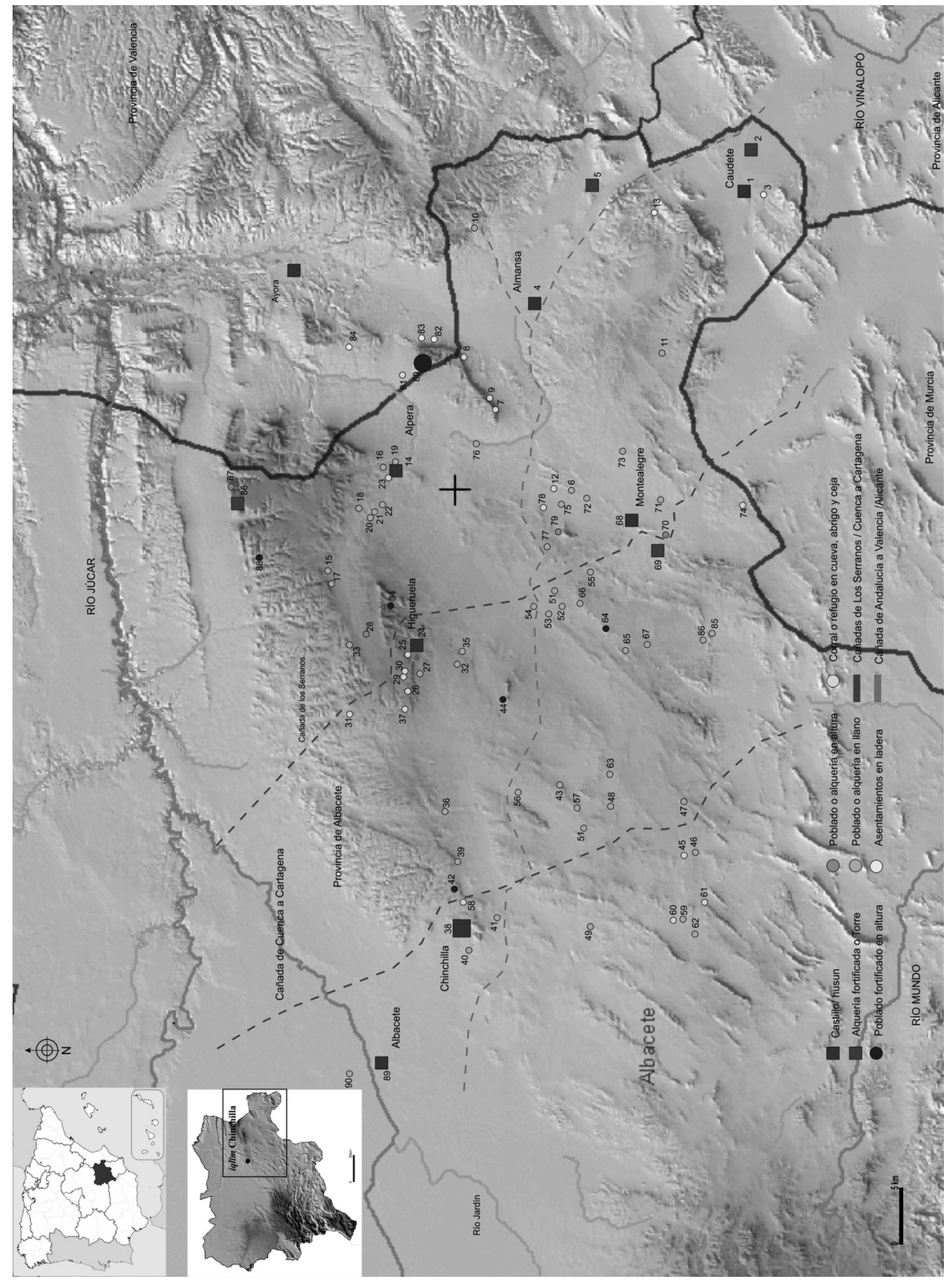

Al-Qantara XXXVIII 2, 2017, pp. 215-259 ISSN 0211-3589 doi: 10.3989/alqantara.2017.008 


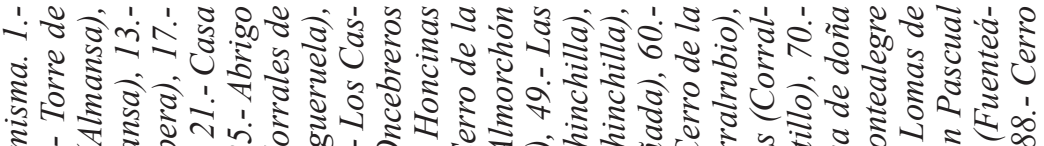

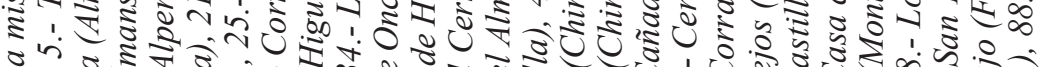
¿

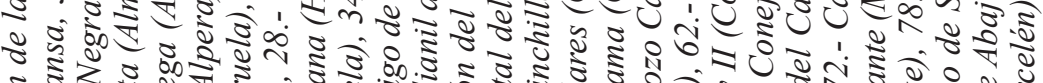

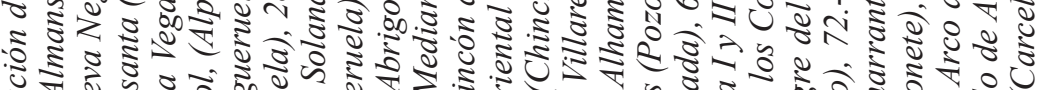

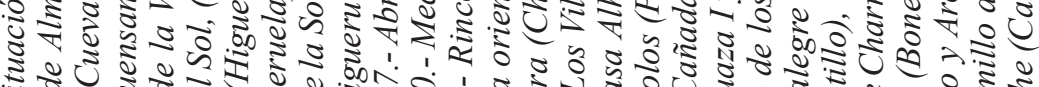

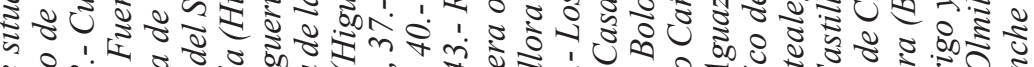

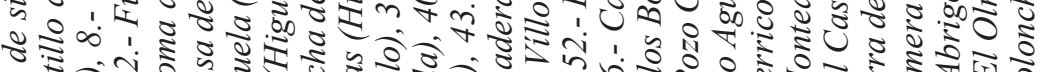

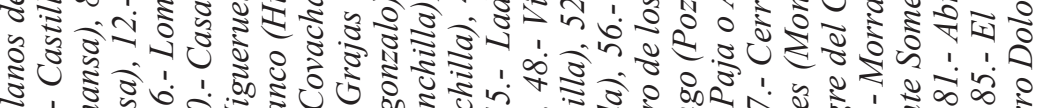

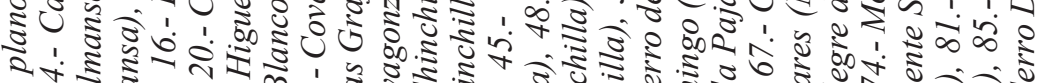

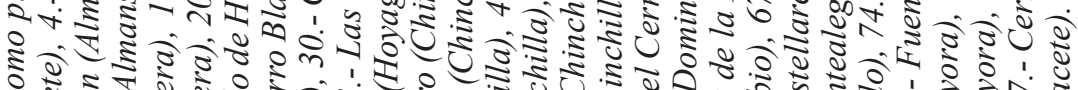

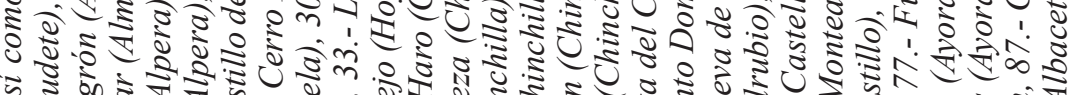

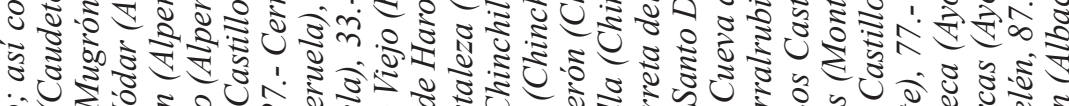

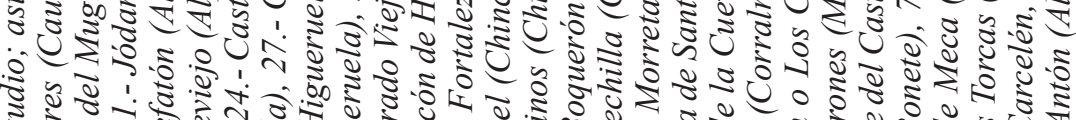

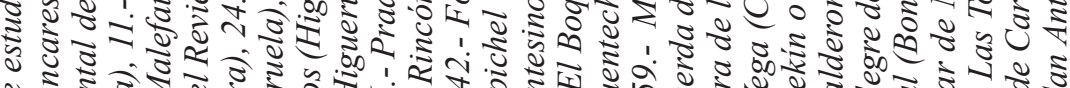

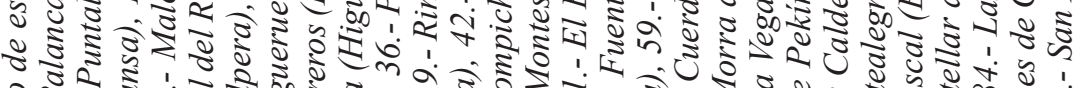

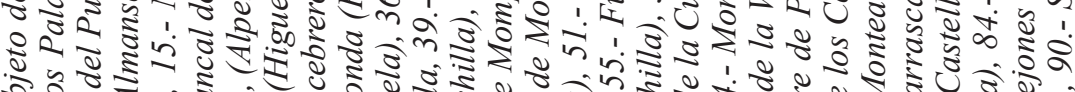

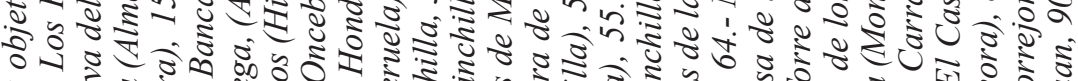

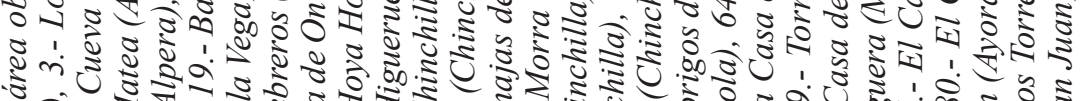

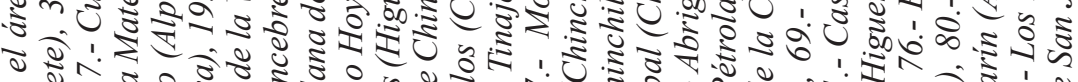

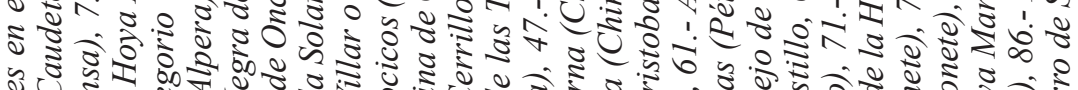

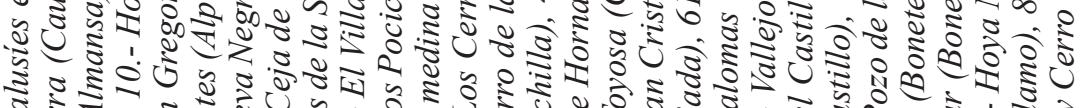

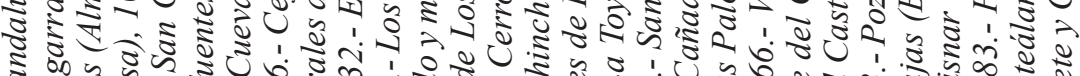
ป

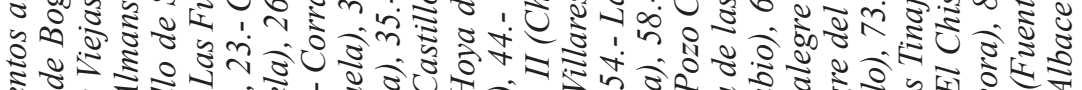

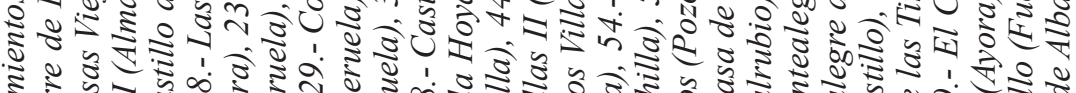

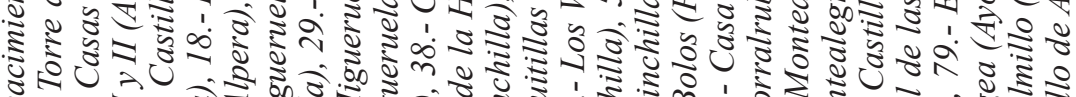

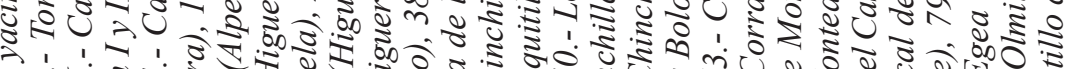

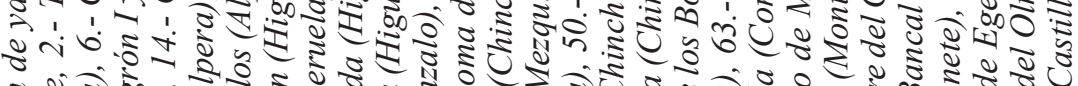

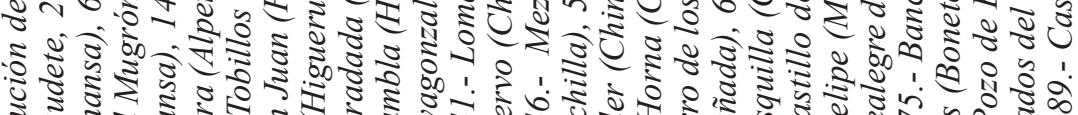

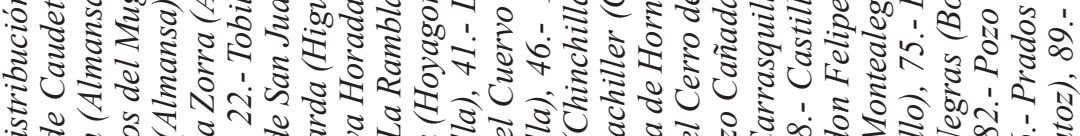

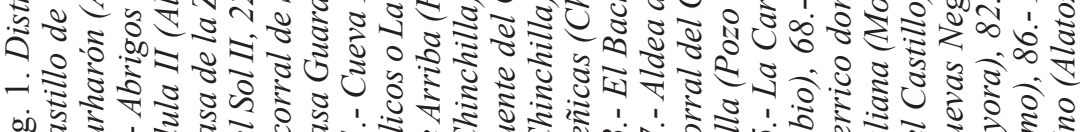

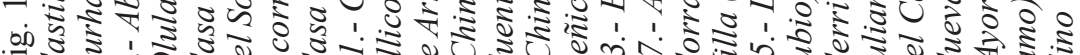

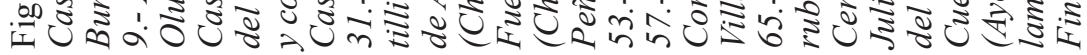

Al-Qantara XXXVIII 2, 2017, pp. 215-259 ISSN 0211-3589 doi: 10.3989/alqantara.2017.008 
y el sureste peninsular con la Meseta y la Alta Andalucía. Por el norte queda delimitado por el cañón del Júcar, entre Alarcón (Cuenca) y la Muela de Cofrentes (Valencia); por el sur linda con el Campo de Hellín, donde se unen los ríos Mundo y Segura; y por el este, con los llanos que llevan hacia La Mancha. El territorio tiene una altitud media por encima de los $750 \mathrm{~m}$, con zonas que superan los $1.000 \mathrm{~m}$, por lo que presenta un clima mediterráneo con cierto matiz continental, con una vegetación donde predomina el encinar y el matorral. La ausencia de cursos fluviales y el relieve endorreico llevan a las aguas pluviales hacia una serie de lagunas, unas salobres y otras de agua dulce en función del sustrato geológico, que han condicionado el poblamiento de la zona en todos los periodos históricos, pues se han escogido sus aledaños, así como los de los escasos manantiales y fuentes, para establecer los asentamientos.

No es de extrañar que en este medio natural la producción agropecuaria de la zona haya estado conformada secularmente por los cultivos de secano - cereales, leguminosas, olivo, almendro y vid-, y la ganadería extensiva - ovejas, cabras, así como ganado vacuno y équido-, estos dos últimos asociados a las tareas de tiro y labranza. Así lo acreditaban los relatores que respondieron a la encuesta de Felipe II: "No se trata otra cosa en esta çiudad sjno labrar y criar ganados mercaderes ay muy pocos todos vjuen de labrança y criança suele venjr a la terçia y granero de esta ciudad un anno con otro seys mjll fanegas de trigo de diezmo pie del buey y rrubjon que esto es el pan que en esta tierra se coge sjembrase trigo mas poco criase en esta tierra ganado ovjuno y cabrio ay en esta tierra muchas necesidades de mulas por ser tantas las labranças..."11. Un dato que creemos muy significativo para comprender el paisaje y su potencial ecológico, es el procedente de los datos estadísticos de usos del suelo en la década de 1980-1990 aportados por el Ministerio de Agricultura ${ }^{12}$, en los que figura que tan solo se dedicaba a la explotación del suelo en forma de huerta el $0,16 \%$ de la comarca, incluyendo los espacios irrigados mediante sistemas de extracción moderna, por lo que la superficie de regadío en época islámica seguramente fue aún bastante menor.

${ }^{11}$ Cebrián y Cano, Relaciones Topográficas, p. 121.

${ }^{12}$ Datos obtenidos del Ministerio de Agricultura, Alimentación y Medio Ambiente a través de GEOPortal. 


\section{Características generales del poblamiento andalusí}

Como demuestra la exigua bibliografía, hasta finales de los años 90 no se tenía prácticamente información alguna acerca de la ocupación del territorio en el iqlìm de Chinchilla ${ }^{13}$. Los únicos datos con que se contaba procedían casi exclusivamente de las fuentes escritas o de la toponimia, y daban como resultado un panorama en el que los asentamientos se concentraban en tono a las vegas de los ríos como el Júcar, Mundo y Segura, quedando entre medias amplios espacios vacíos en los que sólo figuraban algunas alineaciones de localidades jalonando ciertos caminos. Este panorama ha cambiado radicalmente a partir de la prospección sistemática del territorio en cuestión, compuesto actualmente por varios términos municipales, que ha permitido rellenar precisamente uno de esos espacios en blanco alejados de las vegas fluviales ${ }^{14}$. Los yacimientos catalogados hasta la fecha los podemos agrupar en hușūun, alquerías (qurā), en altura o en llano, y cuevas refugio (fig. 1).

La cabeza administrativa de este extenso territorio era la ciudad de Chinchilla (madīnat Šantiŷŷāla o Ŷinŷāla) ${ }^{15}$, considerada como la Saltigi romana, que se hallaba en el límite noroccidental de la cora de Tudmīr, según al-'Ud drī16. Se ubica sobre un espolón rocoso en el extremo suroccidental del conjunto montañoso de Montearagón, en el centro de la actual provincia de Albacete, entre el valle del Júcar y las tierras del Corredor de Almansa que permiten el paso desde el Vinalopó y La Costera o las tierras altas de Murcia hacia el centro de la Meseta ${ }^{17}$. Según al-Idrīsī, Chinchilla era una ciudad (madīna) mediana, defendida por una fuerte y extensa fortaleza, que estaba rodeada por jardines o almunias y arboledas ${ }^{18}$. En Chinchilla nacieron varios personajes entre

\footnotetext{
bacete".

${ }^{13}$ Navarro, "Fortificaciones y asentamientos andalusíes en la actual provincia de Al-

${ }^{14}$ Simón, "El poblamiento islámico en el Corredor de Almansa”; Simón, "Del ḥiṣn alKaras al Castrum de Alcaraz"; Simón, "El poblamiento islámico en Albacete"; Simón, "El poblamiento islámico de las tierras de Alcalá del Júcar"; Simón y Hernández, "Trashumancia y arquitectura".

${ }^{15}$ Acerca de la evolución del topónimo de Chinchilla desde su origen prerromano, véase Chavarría, Cuando Castilla-La Mancha, pp. 145-168.

${ }^{16}$ al-'Udrīi, Tarșī̄, pp. 42 y 63.

${ }^{17}$ Ponce, El Corredor de Almansa.

${ }^{18}$ al-Idrīisì, Nuzhat al muštaq, pp. 175, 195 (texto árabe) y 210, 237 (traducción francesa).
} 
la segunda mitad del siglo X y la primera del siglo XI que alcanzaron la suficiente relevancia como para figurar en repertorios biográficos como los de Ibn Baškuwāl e Ibn al-Farad̄i ${ }^{19}$. De su trama urbana medieval solo podemos identificar en la actualidad la presencia de la alcazaba, en la parte más elevada del cerro; un albacar o espacio abierto en el lado que da al caserío y una medina que se extendía hacia la parte baja del cerro, rodeada de una muralla que partía de la alcazaba ${ }^{20}$. En su interior, los únicos restos de época andalusí que se conocen, hasta la fecha, corresponden a las salas caliente y templada de un baño público $^{21}$.

De la madīna de Chinchilla dependían varios husșūn, situados en los límites del iqlīm, como los de Alpera, Higueruela, Almansa y Carcelén, que ya analizamos en un estudio general sobre las fortalezas de Albacete $^{22}$. La información con que contamos sobre ellos es casi exclusivamente arqueológica, pues no existen datos al respecto en las fuentes árabes, mientras que los documentos del momento de la conquista se refieren de forma genérica a un número elevado de castillos en el entorno de Chinchilla, que fueron tomados al mismo tiempo en 1242 por las tropas santiaguistas del maestre Pelay Pérez Correa: “...pro multo et fauribus seruicio quod michi fecisti in adquisitione Chinchellam et aliorum castellorum illius..."23. Gracias a la arqueología sabemos de la eclosión de estos asentamientos a partir del siglo XI, tal vez en relación con las necesidades defensivas de los habitantes de la región, asociadas a la inestabilidad política de las primeras taifas. A las localidades que ya existían previamente como Chinchilla, Hellín, Alcaraz, Tobarra y Albacete, se sumarán Ayna, Liétor, Letur, Yeste y Riópar, en las cuencas de los ríos Segura y Mundo; así como los castillos de Alcalá, Jorquera y Ves, en el río Júcar (al noreste de la provincia de Albacete). También los husșūn de Yakka (Yecla) ${ }^{24}$ y de Jumilla ${ }^{25}$, en la actual provincia de Murcia, despegaron en el s. XI. En el desarrollo de estos núcleos probablemente también tendría que ver el incremento demo-

${ }^{19}$ Chavarría, Cuando Castilla-La Mancha, p. 156.

${ }^{20}$ Simón, Castillos y torres.

${ }^{21}$ García-Saúco y Santamaría, "Unos baños árabes".

${ }^{22}$ Simón, Castillos y torres.

${ }^{23}$ Pretel, Chinchilla medieval, p. 31.

${ }^{24}$ Ruiz, Ḥișn Yakka, p. 171; Ruiz "Yakka: un castillo de Šarq al-Andalus", p. 78.

${ }^{25}$ Hernández y Simón, El castillo de Jumilla, p. 70. 
gráfico de la zona debido a la colonización del campo que de ellos dependía, que es, precisamente, el tema del que nos ocuparemos en el presente estudio. En cualquier caso, estos poblados fortificados de altura permanecerán en el tiempo, experimentando incluso un cierto crecimiento que alcanzó su apogeo en los momentos previos a la conquista cristiana; después de ésta no todos pervivieron y algunos de ellos, como Higueruela y Carcelén, quedaron despoblados.

A su vez, de estos hus usūn dependerían administrativamente una serie de pequeños núcleos de población, los yacimientos arqueológicos localizados durante las prospecciones intensivas del territorio que hemos venido llevando a cabo, que creemos se pueden identificar como alquerías (qurā); de ellas nos ocuparemos en detalle en los siguientes apartados. Según su emplazamiento, se han podido identificar dos tipos: las que están situadas en altura y las que lo están en llano. Éstas últimas conforman el conjunto más numeroso de asentamientos andalusíes de la zona, principalmente en el espacio intermedio entre los hușūn. Sólo están ausentes en el entorno más próximo de la madīna de Chinchilla, que genera a su alrededor un hinterland deshabitado de unos 10-15 km, es decir, unas dos o tres horas de camino. Ni las unas ni las otras presentan rastros de fortificaciones comunitarias, elementos que suelen ser característicos de los asentamientos campesinos de carácter segmentario ${ }^{26}$.

Desgraciadamente, las fuentes escritas no aportan información alguna acerca de este poblamiento, pues no se conservan textos castellanos post-conquista como los repartimientos, ni tenemos tampoco descripciones de autores árabes. El recurso de la toponimia es también limitado, puesto que la zona quedó casi totalmente desprovista de población, tanto mudéjar como cristiana, a partir de mediados del siglo XIII, lo que debió de ocasionar la desaparición de la mayor parte de los nombres geográficos. Los escasos datos existentes fueron analizados por Pocklington en su trabajo sobre toponimia ibérica, latina y árabe de la provincia de Albacete, en el que se muestra la inexistencia de nombres de origen tribal árabe o bereber; la mayoría designan elementos del paisaje, accidentes geográficos o apelativos individuales ${ }^{27}$. Unos pocos resultan algo más informativos, pues aluden a las caracte-

${ }^{26}$ Barceló, Kirchner y Navarro, El agua que no duerme, pp. 62 y 63.

${ }^{27}$ Pocklington, "Toponimia". 
rísticas o naturaleza del asentamiento, como Bete (Higueruela) del árabe bayt "casa"; o Zucaña (Almansa), que remontaría al diminutivo sukayna del vocablo sakan "vivienda, morada". Quizás estos topónimos puedan asociarse con algunos asentamientos andalusíes de tamaño mínimo, consistentes en una o dos casas aisladas, que eran relativamente abundantes a juzgar por la información proporcionada por las prospecciones. El nombre del pago de Alcoraya, ubicado 2,5 km al NE de Caudete, procede claramente del árabe al-Qurayya "la pequeña alquería", diminutivo de qarya "alquería, caserío", y podría estar en relación con el tipo de asentamiento en llano que hemos localizado recurrentemente en las prospecciones ${ }^{28}$.

Finalmente, son muy abundantes las cuevas refugio ligadas a las actividades ganaderas y silvícolas. Su uso pudo ser estacional y en algunas ocasiones permanente, tal y como lo muestran las construcciones que se levantaron al exterior, ampliando y mejorando las condiciones de vida de sus moradores y relegando al abrigo a una utilización exclusivamente ganadera, como corral. Ejemplo de ello sería la Cueva Negra del Mugrón, entre Almansa y Ayora, al exterior de la cual se construyó una edificación con una crujía compartimentada en tres estancias para el refugio y residencia de sus moradores, y un patio o corral anexo, en el cual se levantaron pequeñas estancias para los aperos, o para las necesidades específicas del ganado, como las parideras. Por su tamaño y ubicación parece lógico suponer que estarían relacionadas con las alquerías próximas del llano, si bien es posible que tuvieran una cierta autonomía funcional. Son especialmente abundantes en la cara meridional de las sierras de Chinchilla, Higueruela y Carcelén. En algunas ocasiones se documentan en la cara norte de los relieves, a cotas de altura considerables, circunstancia que debe de ponerse en relación con el aprovechamiento de los pastos de verano ${ }^{29}$.

\section{Las alquerías en altura}

Así denominamos a un conjunto de asentamientos enclavados en lugares elevados, generalmente sobre los 1.000 m.s.n.m., lo que les

${ }^{28}$ Pocklington, "Toponimia”, p. 148.

${ }^{29}$ Simón y Hernández, "Trashumancia y arquitectura". 
sitúa por encima del fondo del llano entre 100 y $300 \mathrm{~m}$. Sus tamaños son dispares, desde casi 13 hectáreas, en el caso del El Castellar de Meca (Ayora), donde se incluyen las viviendas dispersas, los corrales y las amplias zonas vacías entre las casas, hasta los $3.000 \mathrm{~m}^{2}$ de Mompichel o Cerro de las Tinajas (Chinchilla), los $3.500 \mathrm{~m}^{2}$ del Cerro de La Fortaleza (Chinchilla) o los $4.500 \mathrm{~m}^{2}$ de Los Castillicos (Higueruela); suelen contar con unas 30 ó 40 casas. Una variante de estas alquerías en altura la conformaría un conjunto de asentamientos de menor tamaño que los anteriores, pues no llegan a las 10 casas y una extensión que ronda los 1.000 a $2.000 \mathrm{~m}^{2}$. Se sitúan en las laderas de pequeñas colinas o cerros sin más defensas que las pendientes naturales $\mathrm{y}$, ocasionalmente, una cumbre, habitualmente reducida y sin señales de ocupación, que pudo haber servido de refugio, aunque no existen evidencias que lo confirmen. Ni siquiera el dominio estratégico que podría derivarse de su ubicación en alto justifica su emplazamiento pues en algunos casos quedan sus campos visuales ocultos por elevaciones próximas, o abiertos a espacios sin mayor interés. Sólo el despoblado andalusí del Castellar de Meca, que ocupaba el emplazamiento del impresionante núcleo ibero-romano, presenta indicios de haber reutilizado alguno de los aljibes y de los muros de defensa de las fases previas.

Con independencia de la extensión del asentamiento, las características de los edificios domésticos son similares: los de menor tamaño compuestos por una sola nave rectangular con el vano abierto hacia el sur o sureste, aparentemente sin compartimentaciones interiores, y otros mayores configurados por un perímetro rectangular que comprende una crujía de dos o tres estancias con vanos abiertos a un gran corral o patio. En ambos casos las viviendas suelen estar agrupadas a modo de proto-manzanas compuestas por edificios de morfología y orientación similares, si bien las casas no comparten paredes medianeras sino que se presentan más o menos aisladas, separadas por espacios variables que oscilan entre algunos metros e incluso unos cuantos centímetros.

Un buen ejemplo de este tipo de asentamientos sería Los Castillicos de Higueruela, situado en la ladera de una colina defendida por dos barranqueras que la flanquean. Las casas se sitúan en la ladera oriental, protegidas de los vientos dominantes por el farallón rocoso de la cumbre (fig. 2). Se trata de viviendas con corral, adosadas las unas a las 

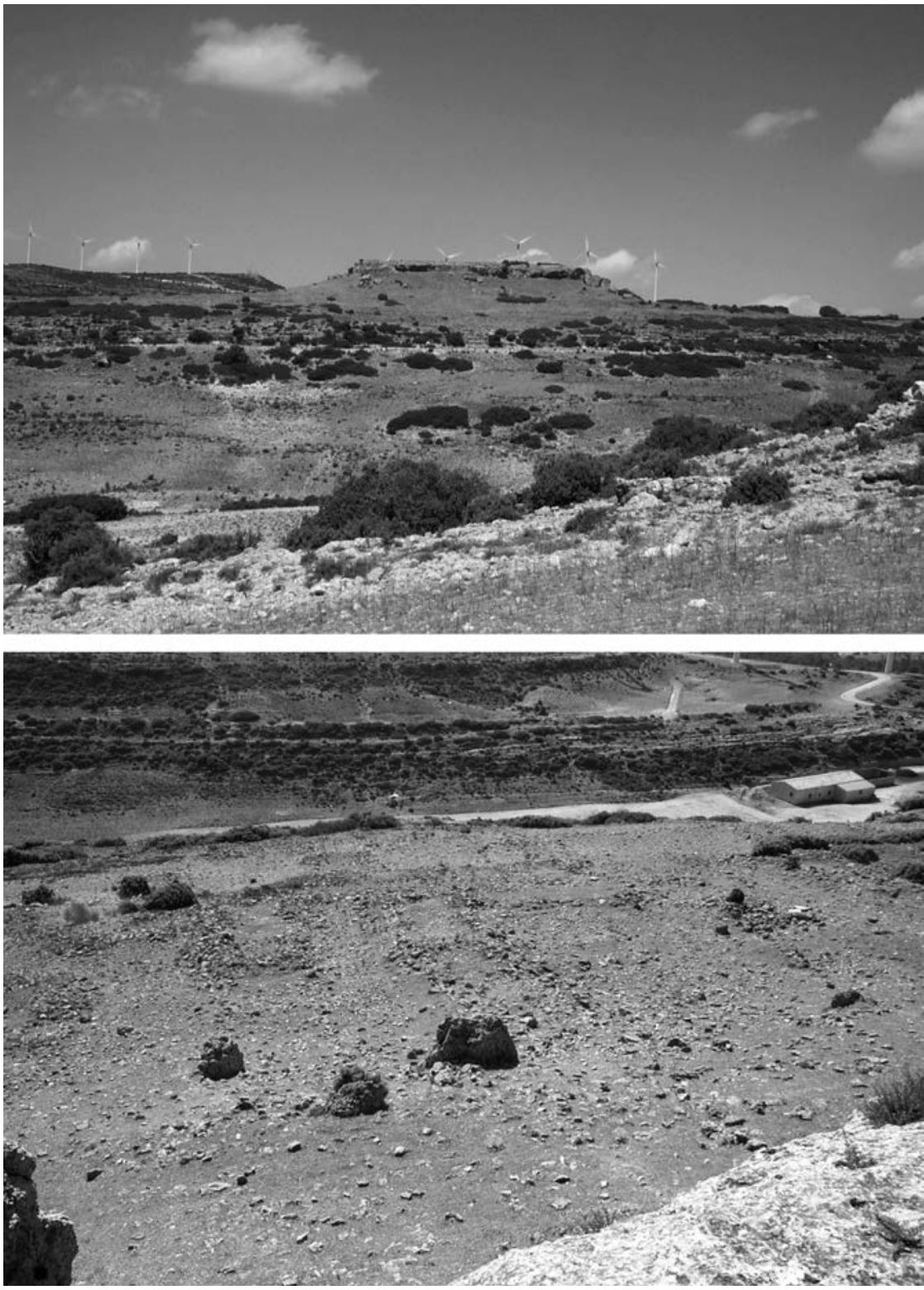

Fig. 2. Los Castillicos (Higueruela). En el centro de la imagen superior aparece el cerro el que se encuentra el yacimiento. El caserío se levantaba en la ladera pero no hay restos de ocupación de la parte superior del mismo. En la imagen inferior se aprecia el caserío visto desde la cima del cerrete.

Al-Qanțara XXXVIII 2, 2017, pp. 215-259 ISSN 0211-3589 doi: 10.3989/alqantara.2017.008 
otras y dispuestas de forma escalonada. El conjunto queda delimitado, con respecto a la parte inferior de la ladera, por un escalonamiento rocoso que le pudo servir de defensa natural quizás completado en algún sector mediante tramos de muro. Sin embargo, la parte más accesible al poblado, por el noreste, no parece presentar restos de una posible muralla, cerca, o cierre de algún tipo.

A pesar de su emplazamiento, no podemos identificar los asentamientos en cuestión como hușūn dado que no presentan las características de éstos: son de tamaño excesivamente reducido y no poseen elementos defensivos construidos por la mano del hombre, como recintos amurallados para proteger el caserío, celoquias o aljibes comunitarios.

\section{Las alquerías en llano}

Cabe distinguir entre las que contaron con una torre defensiva y las alquerías que carecieron de defensas. Las primeras conforman un grupo muy reducido, entre las que podemos mencionar Burjaharón o Torre Grande (Almansa), la Torre de Pechín (Montealegre) y el Torrejón de Carcelén. En un emplazamiento algo más periférico estaría la alquería de Bugarra (Caudete), a oriente del territorio objeto de estudio pero ya en el ámbito de la supuesta medina de Villena (Bilyāna). Se ubican junto a caminos y vías de comunicación importantes, por lo que parece probable que acogieran un manzil o posada. El registro material permite fechar su ocupación avanzado el siglo XII y durante la primera mitad del XIII, si bien es posible que dataran de fechas anteriores y que fuera en esta fase final de intensa amenaza cristiana cuando se fortificaron. Así parece constatarse en la alquería de Bugarra (Caudete), la única en la cual se ha podido efectuar una mínima intervención arqueológica, que confirma una primera fase de la alquería sin fortificación y una segunda en la que se construye la torre y su cerca, probablemente como resultado de la proximidad de los contingentes cristianos en su avance a la conquista del reino musulmán de Valencia y los preparativos para el asalto final al de Murcia $^{30}$.

Las segundas están igualmente situadas en llano, pero carecen de elementos defensivos. El número de las que conocemos es cada vez

${ }^{30}$ Simón, “Sax, Salinas y Villena". 
mayor, pese al sesgo de la información aportada por las prospecciones debido a que estas alquerías se conservan peor que las emplazadas en altura por causa de las intensas tareas agrícolas de las últimas décadas. Algunas de ellas las hemos estudiado más en profundidad ${ }^{31}$, como La Toyosa (figs. 3 y 4) y El Boquerón (Chinchilla); La Graja (fig. 5) y el Villar de Hoya Honda (Higueruela) (fig. 6). O están en fase de estudio, como los Pocicos de Higueruela, la Carrasquilla, el Vallejo de la Casa de la Vega y el Cerrico de los Conejos (Corral Rubio); la Casa del Sol I y II, la Casa de la Zorra y Malefatón (Alpera); Hoya Matea (Almansa); la Rambla del Charco (El Bonillo); Dolonche (Carcelén) (fig. 7); y los conjuntos de Los Villares de Munera (figs. 8) y Lechina (Munera). De tamaño variable, algunas de ellas parecen haber contado con escasamente una decena de casas, como por ejemplo La Toyosa (fig. 4); mientras que otras debieron de alcanzar las 40 ó 50, como sucedía en Los Villares del Bachiller (Chinchilla) (fig. 9), aunque en la mayoría de los casos el número de viviendas oscilaría entre ambas cifras.

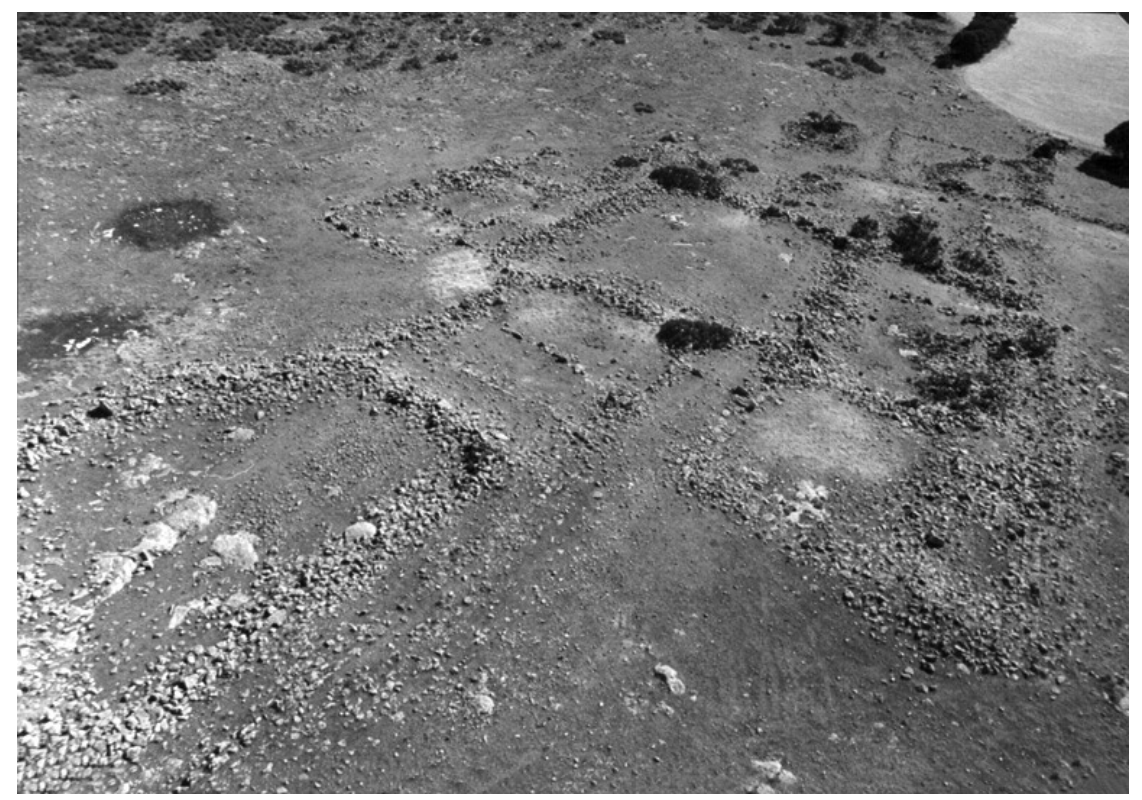

Fig. 3. La Toyosa (Chinchilla). Vista aérea de algunas de las casas.

${ }^{31}$ Simón, "El poblamiento islámico en Albacete". 

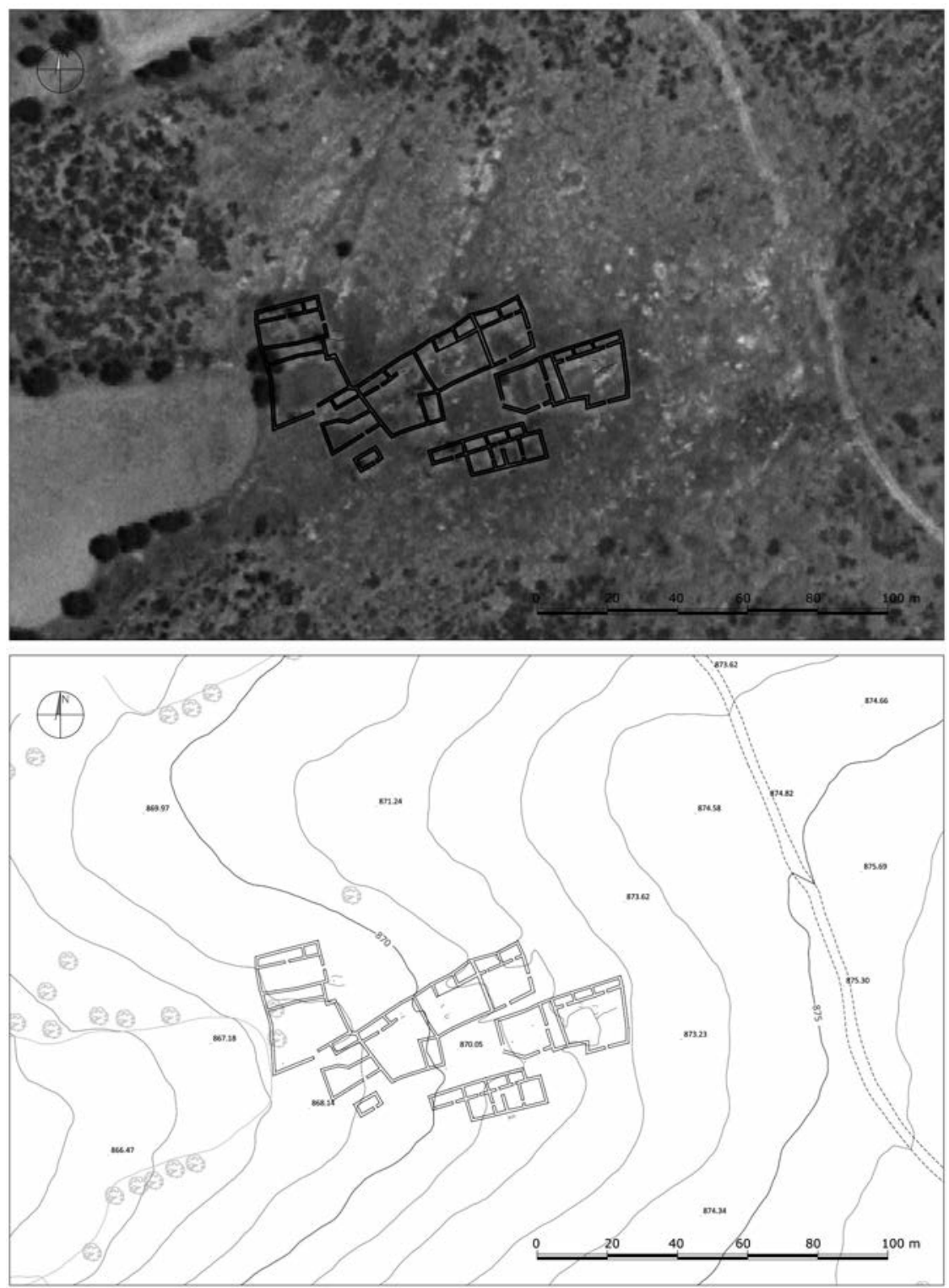

Fig. 4. La Toyosa (Chinchilla). Imagen superior: ortofotografía del yacimiento con la planimetría superpuesta. Imagen inferior: plano topográfico. 

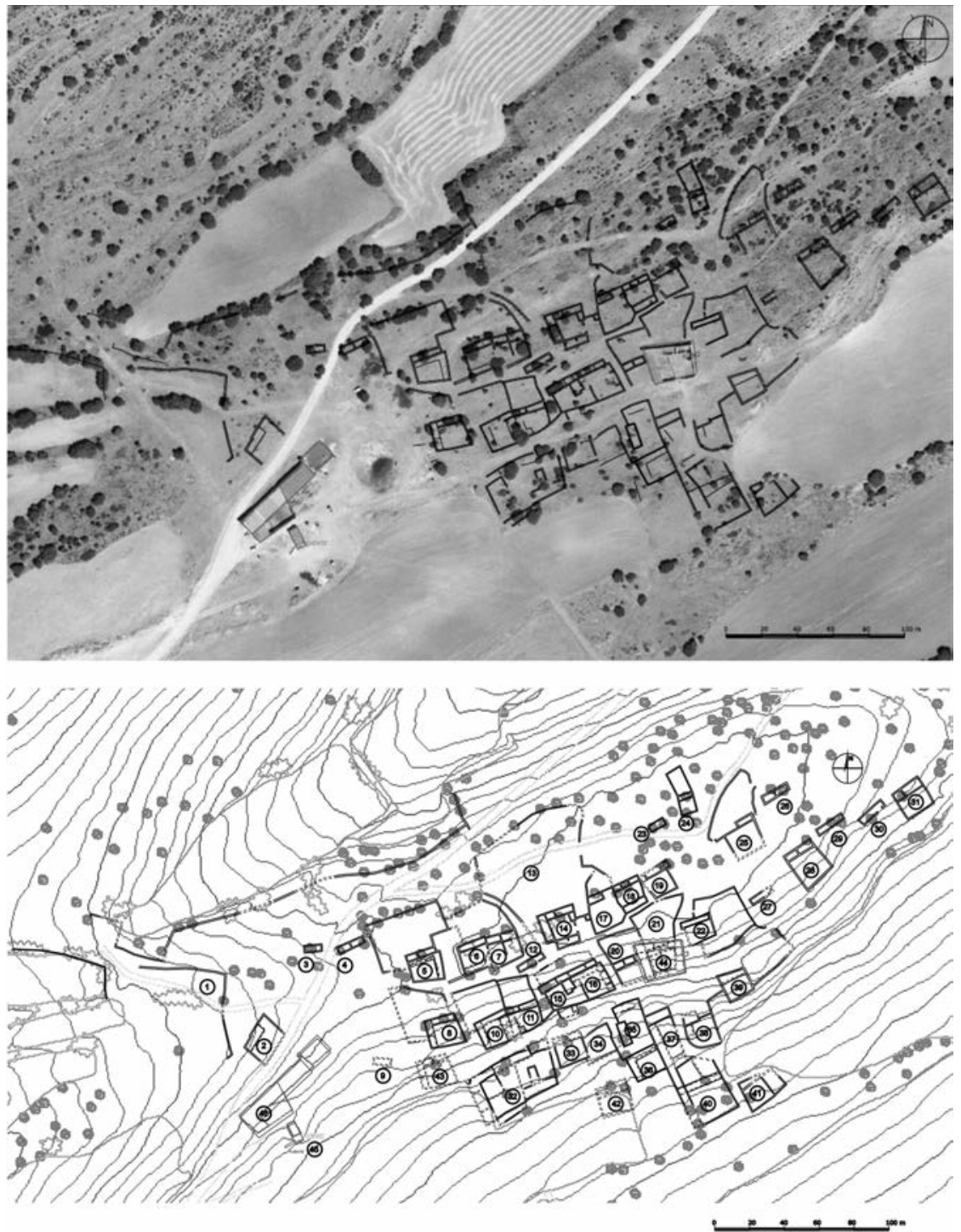

Fig. 5. La Graja (Higueruela). Imagen superior: ortofotografia del yacimiento con la planimetría superpuesta. Imagen inferior: plano topográfico. 

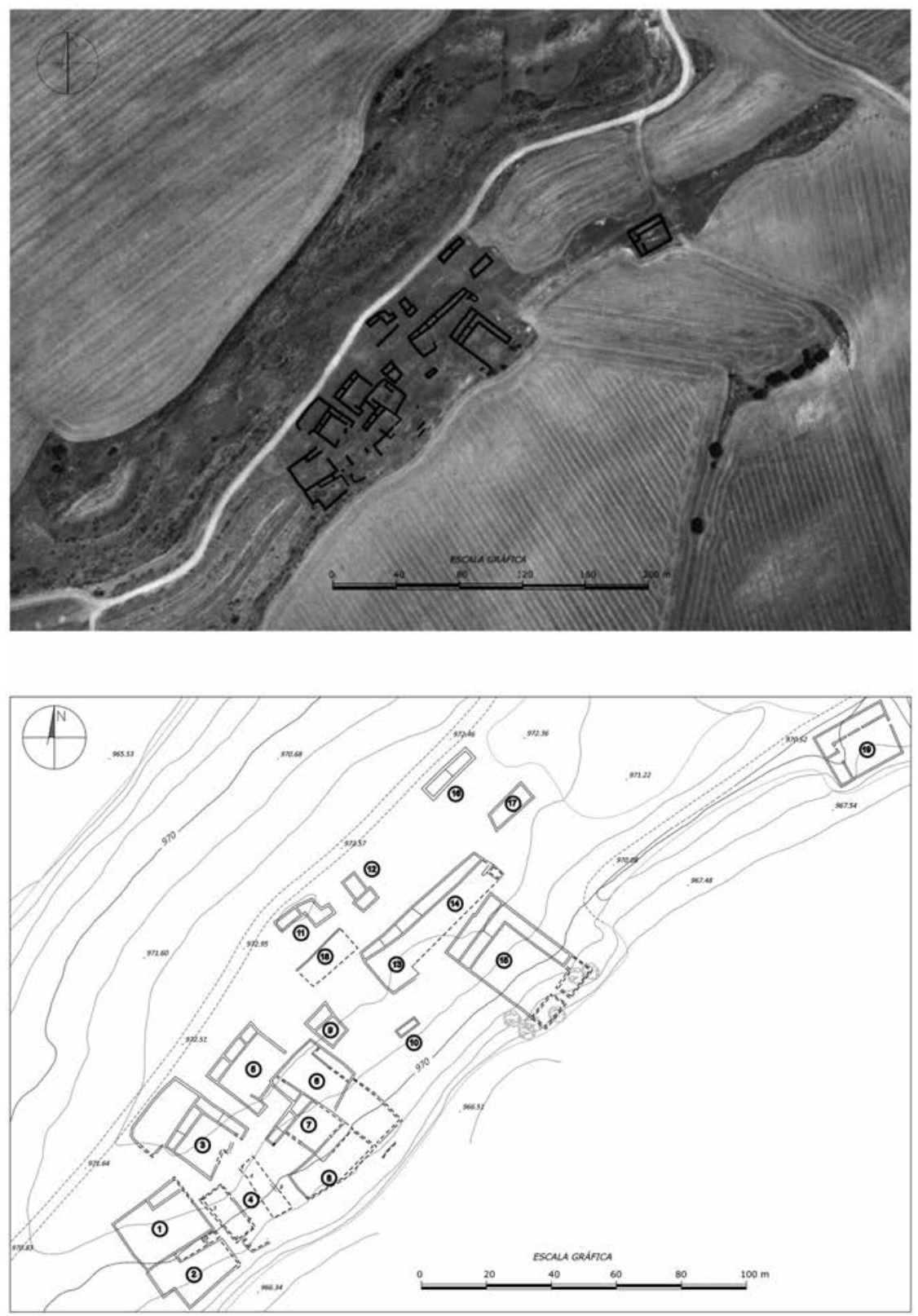

Fig. 6. El Villar de Hoya Honda (Higueruela). Imagen superior: ortofotografía del yacimiento con la planimetría superpuesta. Imagen inferior: plano topográfico. 

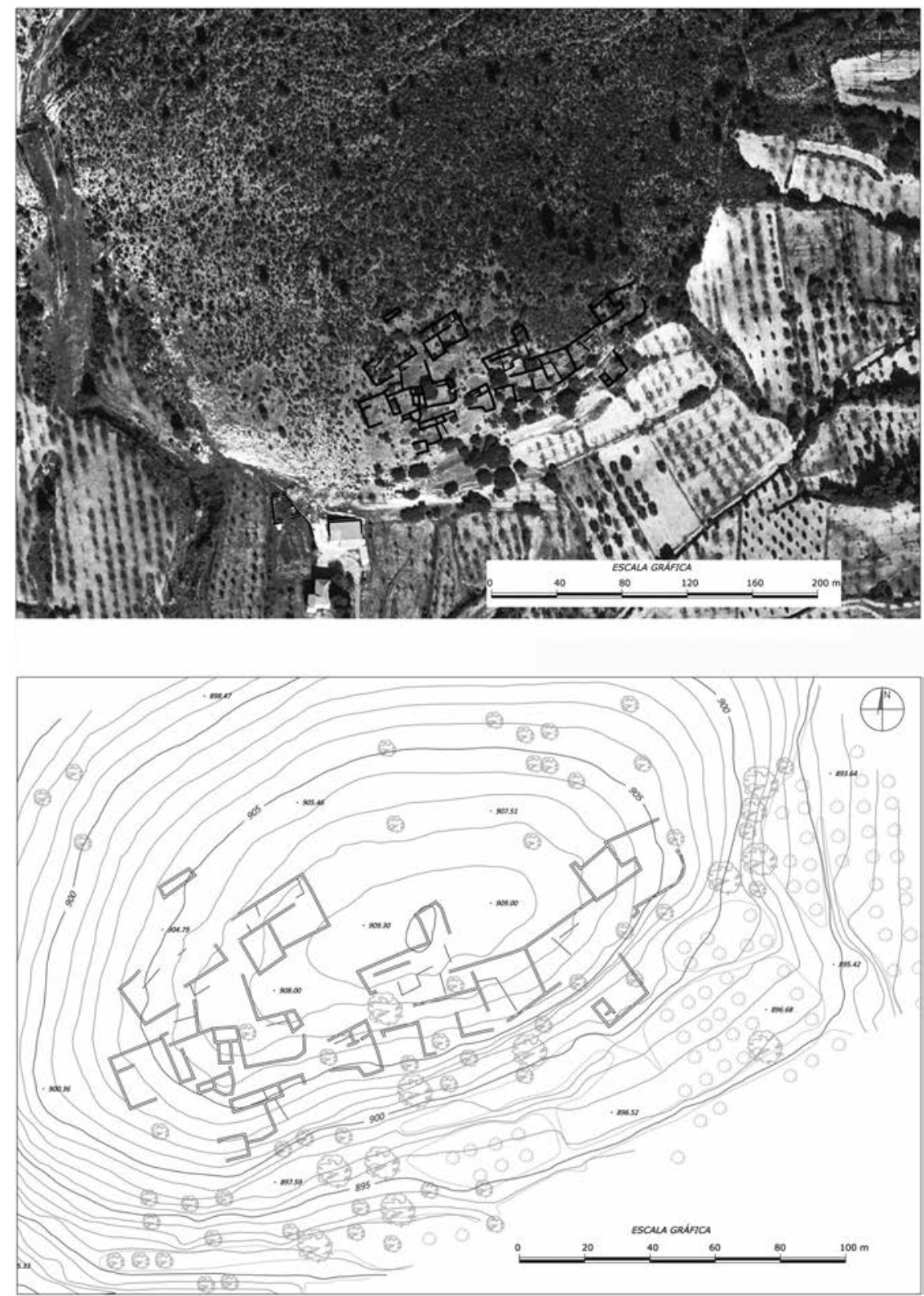

Fig. 7. Dolonche (Carcelén). Imagen superior: ortofotografia del yacimiento con la planimetría superpuesta. Imagen inferior: plano topográfico. 


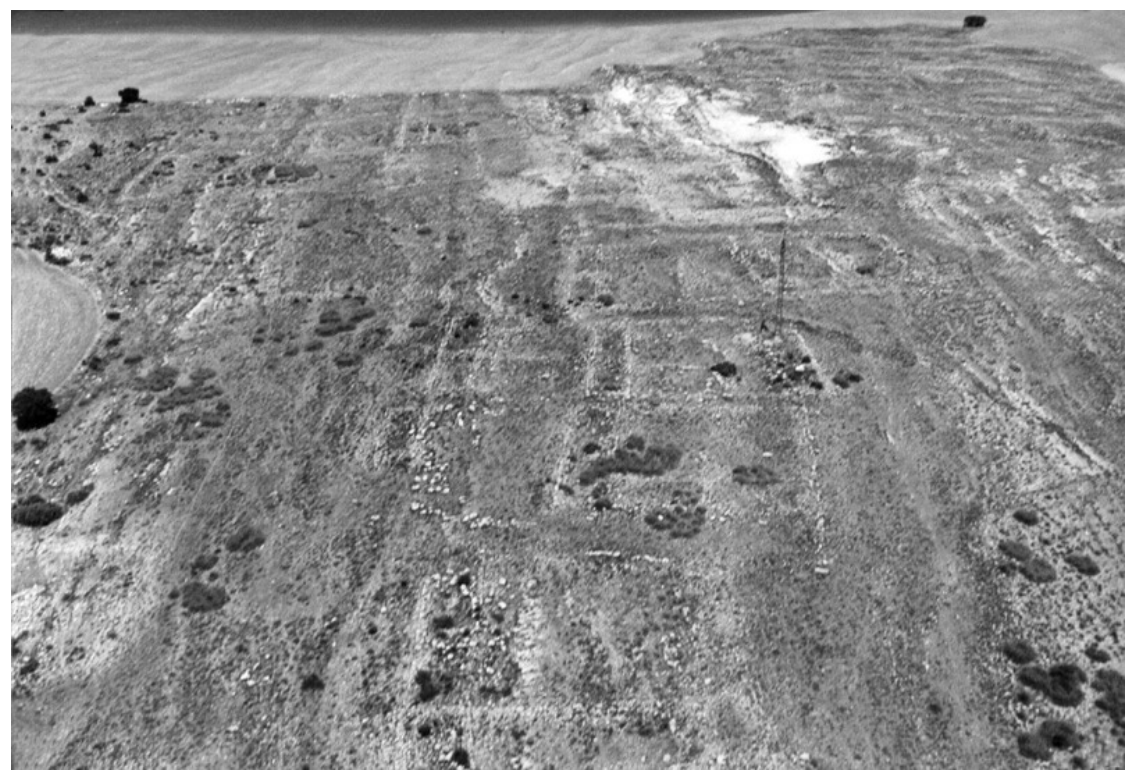

Fig. 8. Los Villares de Munera. Vista aérea de algunas de las casas.

Si observamos su distribución en el mapa (fig. 1) podemos apreciar que aparecen agrupadas geográficamente en torno a las cañadas de la zona, en conjuntos de 5 a 8 asentamientos que incluyen alquerías y cortijos compuestos por solo una o dos viviendas, que quizás pudieron compartir algún tipo de establecimiento comunitario, como un oratorio o un refugio en algún punto bien protegido para las ocasiones en que hubiera peligro. Así podrían interpretarse las agrupaciones de alquerías en torno a algunos hus ūn, como los de Higueruela y Alpera. Este modelo de organización del poblamiento ha sido bien estudiado en otros puntos del oriente de al-Andalus ${ }^{32} y$, por tanto, es posible que también se diera en el territorio examinado; aunque en el estado actual de la investigación no tenemos pruebas que nos permitan aseverarlo.

Todas estas alquerías muestran, en general, unas características comunes. Muchas se encuentran en tierras que aún hoy en día, pese a la mecanización del campo, son espacios baldíos, bien por situarse sobre

\footnotetext{
${ }^{32}$ Cressier, "Fonction et évolution du réseau castral".
} 

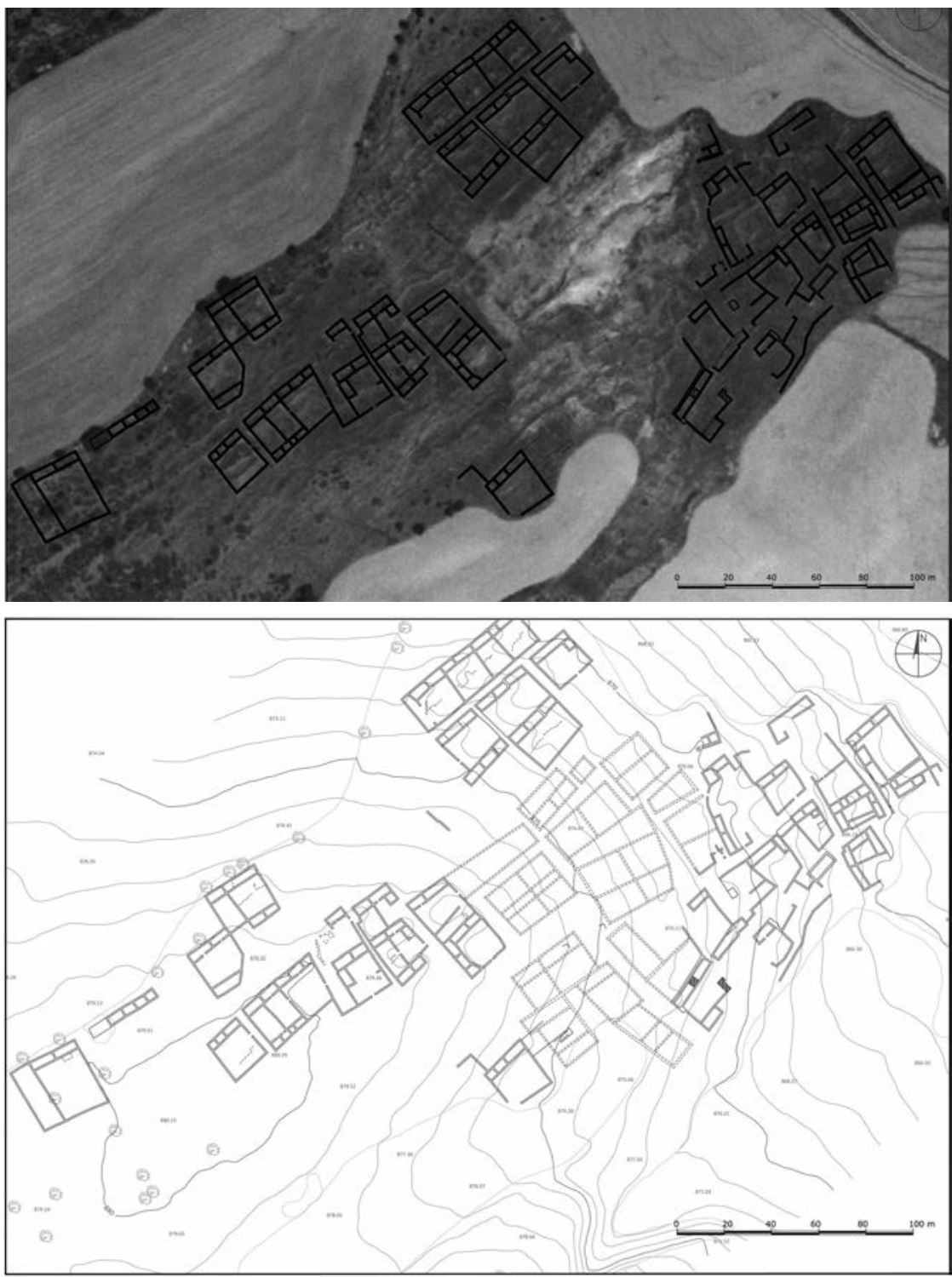

Fig. 9. Los Villares del Bachiller (Chinchilla). Imagen superior: ortofotografia del yacimiento con la planimetría superpuesta en su estado actual; como se puede observar, la parte central del mismo se encuentra destruida debido a remociones de tierra efectuadas a comienzos de los años 70. Imagen inferior: plano topográfico; hemos restituido en discontinua los edificios del sector central a partir de fotografias aéreas anteriores a su destrucción. 
lomas donde el afloramiento del sustrato rocoso y la escasez de suelo las han hecho inservibles para el cultivo, bien por tratarse de zonas de monte bajo, tradicionalmente dedicado al pastoreo, pudiendo encontrarse en los límites de grandes propiedades que han usado sus restos como majanos donde acumular las piedras de los bancales. Se emplazan en terrenos ondulados con suave pendiente, especialmente en lugares protegidos de los vientos dominantes del noroeste y norte, en donde tengan asegurado el abastecimiento de agua mediante pozos y manantiales. La mayoría de las alquerías evitan ocupar las tierras de labor más aprovechables y las zonas de charcas y lagunas. Son excepcionales las que están junto a pequeñas vegas, como la de Tobillos en Alpera $^{33}$, que pudieron explotar espacios agrícolas irrigados de escasa extensión y sin posibilidades de ampliación debido a razones orográficas - la escasa pendiente y unos márgenes con escarpes rocosos-, así como al escaso caudal disponible y a un sustrato geológico de las posibles áreas de expansión carente de suelos aptos para el cultivo.

Desde el punto de vista urbanístico, los asentamientos muestran un estado temprano de la evolución del caserío, caracterizado por una cierta dispersión de los edificios, sobre todo en la periferia del núcleo central, y la existencia de espacios de paso amplios e irregulares que aún no presentan las alineaciones de fachada propias de una calle formada. Los grupos de casas - de patio central, en ocasiones con un gran corral anexo-, configuran proto-manzanas que se extienden siguiendo las curvas de nivel, conformando así bandas edificadas entre las que se sitúan las áreas de paso. Estas agrupaciones de viviendas están cortadas por algunos callejones perpendiculares a la pendiente, servidumbres de paso angostas que demuestran que, incluso en este urbanismo en formación, las viviendas tendían a expandirse en la misma dirección que las curvas de nivel.

Aunque muy minoritarios, se distinguen también algunos edificios de reducido tamaño y planta simple de forma rectangular, que se emplazan en zonas periféricas o de forma aislada en áreas centrales, sin otro tipo de construcciones asociadas. Cabe la posibilidad de que se trate de viviendas en su estadio más simple, carentes de patio, corral y de otras crujías; un tipo de casa de módulo unicelular que es, según Sonia Gutiérrez, un espacio plurifuncional, al que se accedía directa-

${ }^{33}$ Simón, Castillos y torres, pp. 167-266. 
mente desde el exterior y en cuyo interior se repartían varios sectores de actividad doméstica en torno al elemento nuclear que es el hogar ${ }^{34}$. No obstante, la falta de excavaciones impide saber con certeza la función a que estaban destinados y no se pueden descartar otros usos.

\section{La arquitectura doméstica}

En muchas de las alquerías se aprecian claramente las plantas de las viviendas, su compartimentación interna y su distribución. La mayoría de las casas son de planta cuadrangular, con un amplio espacio abierto a modo de patio que ocupa dos tercios de la superficie total, al que se abren una o dos crujías de estancias rectangulares con un vano cada una de ellas, en ocasiones interconectadas entre sí. Las puertas al patio se suelen orientar al sur y la trasera de las estancias al norte o noroeste para protegerse de los vientos dominantes. Los vanos están definidos por dos piedras en vertical a modo de jambas y una horizontal que sirve de umbral. Los muros cuentan con un zócalo construido mediante dos hiladas de piedras de mediano y gran tamaño, a dos caras, en ocasiones rellenas por ripio. No se aprecian niveles de adobes, tapiales o cualquier otro tipo de acumulación procedente de la descomposición de las estructuras, por lo que todo parece indicar que se trata de paramentos realizados en piedra seca o escasa de mortero, con cubierta de vigas de pino, ramaje y tierra. El tamaño de algunos espacios imposibilita su techado, por lo que todo parece indicar que se trata de corrales, mientras que otros de menor tamaño podrían formar parte de unidades complejas constituidas por dos o más estancias. Muchas de las habitaciones rectangulares presentan una compartimentación en el último tercio del espacio, o una construcción, hoy macizada por los derrumbes, de planta cuadrangular en una de sus esquinas. Se trata de una arquitectura uniforme, extremadamente sencilla y tradicional, al menos a juzgar por los restos que se conservan, que emplea la piedra caliza de la zona pero no el adobe o el tapial; a diferencia de la arquitectura del mundo ibérico o romano de la región, que levanta los muros con un zócalo de piedra y alzados de adobes. No obstante, solo futuras excavaciones arqueológicas podrán confirmar que el aparejo construc-

${ }^{34}$ Gutiérrez, "Casa y casas”, p. 22. 
tivo es exactamente el descrito y que la erosión no ha hecho desaparecer obras de tierra.

En la mayoría de las viviendas que hemos venido examinando no se puede decir que el patio ocupe una posición central, como sucedería en el modelo más arquetípico, puesto que el tipo más frecuente en estas alquerías está compuesto por la yuxtaposición de una crujía y un amplio patio o corral rectangular delimitado por muros por 3 de sus lados. Ocasionalmente pueden aparecer dos crujías, afrontadas o en L, en torno al espacio abierto, pero no da la impresión de que estemos ante crujías que se han agregado paulatinamente delimitando un "protopatio" 35 , puesto que las plantas de las casas no presentan el carácter orgánico característico de este proceso de formación doméstica sino que se trata de recintos de tendencia cuadrangular, bastante regulares, que parecen haberse definido antes de la división de los espacios interiores. Esta particularidad se debe, creemos, a que desde el momento en que se decide la creación de la vivienda es necesario delimitar una parte importante de la misma como corral para el ganado. De hecho, la planta de estas casas es muy parecida a la de los corrales domésticos que Lorenzo Cara ha estudiado en las tierras del antiguo reino nazarí, edificios también extremadamente sencillos que contaban con un recinto cuadrangular al que podía abrirse algún tinado y una o dos naves o "palacios"36. Este tipo de construcciones son exponente, en cualquier caso, de una ganadería local, riberiega o estante, que no necesita de grandes cercados como los albacares o las redondas, propios de la ganadería trashumante o incluso transterminante. La crujía oblonga se sitúa preferentemente en el frente norte y puede estar compartimentada en dos piezas mediante un muro de partición. Estamos, en definitiva, ante un modelo doméstico con amplios patios y estancias escasas pero extremadamente funcionales, que permitía la cohabitación familiar pero también la presencia de ganado y la gestión de actividades agrícolas como el almacenamiento y algunas actividades artesanales relacionadas, que es típico de contextos rurales, e incluso de algunos ambientes urbanos de época temprana.

Finalmente, cabe señalar que las alquerías de mayor tamaño parecen haber tenido una mayor pervivencia, lo que dio lugar a una evolución

${ }^{35}$ Gutiérrez, "Casa y casas".

${ }^{36}$ Cara, "Huellas de pastores". 
hacia un tipo de viviendas más regularizado, tanto en su organización interna como en el tamaño y distribución en el espacio urbano. Estas características presenta el sector noroccidental de viviendas de la alquería de Los Villares del Bachiller, a diferencia de las situadas en la zona sudoriental de la misma. En las primeras se observa una disposición alineada de las estructuras en un eje que iría de suroeste a noreste, creando una serie de alineaciones más o menos en paralelo. Las dimensiones de las viviendas son relativamente homogéneas, con una crujía de unos 19,5 m de largo por $3 \mathrm{~m}$ de ancho, es decir unos $60 \mathrm{~m}^{2}$, compartimentada de manera más o menos homogénea en varias estancias, mientras que los patios o corrales suelen tener como media unos $17 \mathrm{x}$ $14 \mathrm{~m}$, unos $240 \mathrm{~m}^{2}$. Por el contrario, el sector sudoriental muestra una configuración irregular pues las casas no se ordenan de acuerdo con una determinada alineación, sino que parecen ser fruto de la construcción puntual, de segregaciones o del aprovechamiento de espacios residuales que han quedado rodeados por otras viviendas levantadas en diferentes momentos. Ello a pesar de que los edificios presentan una organización de espacios residenciales y patios-corrales, similar a la de los primeros.

Para poder valorar adecuadamente la modestia de la arquitectura doméstica de estas alquerías y la fuerte orientación productiva que revela la distribución de sus espacios, puede ser de utilidad compararla con la de otros yacimientos análogos. Así, las 9 casas documentadas en la alquería del siglo XI de Foietes de Dalt (Villajoyosa, Alicante): cuentan con patio central en torno al que se disponen entre 2 y 4 crujías $^{37}$. Las dependencias apenas muestran jerarquización y elementos que permitan distinguir la función a la que se destinaban, aunque la observación de las plantas permite deducir la existencia de letrinas y establos, así como otras piezas mayores que pudieron funcionar como cocina o salón. Las casas de los despoblados albaceteños resultan indudablemente pobres en comparación con las de Foietes, que a su vez son ligeramente más modestas que las de L'Almisserà, la alquería situada a sólo 150 metros de la primera, que deben datarse ya en los siglos XII-XIII y que son equiparables a sus contemporáneas de asentamientos como el hiṣn de Yakka ${ }^{38}$ o la Villa Vieja de Calasparra ${ }^{39}$. Todas ellas resultan

${ }^{37}$ García, Llorens y Pérez, "L’Almisserà", pp. 90-94.

${ }^{38}$ Ruiz, Hiṣn Yakka; Ruiz "Yakka: un castillo de Šarq al-Andalus".

${ }^{39}$ Pozo, "La alquería islámica de Villa Vieja". 
más pobres que las de Siyāsa cuya riqueza ornamental y la proliferación de dependencias como los salones-miradores resultan difíciles de conciliar con los rigores de la vida de los campesinos medievales ${ }^{40}$. En resumen, las viviendas de los yacimientos albaceteños que venimos analizando muestran una especial sobriedad que se manifiesta en los aparejos empleados, en la ausencia de cualquier elemento decorativo e, incluso, en la modestia de los ajuares cerámicos recuperados. Estas características, junto con la polifuncionalidad de los espacios y su escasa especialización, según parece desprenderse exclusivamente del análisis de las plantas, confirman el carácter fuertemente rural de esta arquitectura, que contrasta con la de las alquerías y huușūn contemporáneos como los anteriormente citados, en los que los modelos domésticos se aproximan bastante a las casas urbanas. Parece lógico deducir que fueron razones geoeconómicas las que imprimieron tales diferencias: mientras que aquellas poblaciones explotaban fértiles huertas irrigadas mediante sistemas hidráulicos desarrollados, en expansión desde el siglo X; los asentamientos albaceteños se limitarían al aprovechamiento de unos recursos mucho más modestos y menos diversificados que se basarían en la ganadería y la agricultura de secano.

\section{Cronología}

Para fechar estas alquerías no contamos con información alguna procedente de las fuentes escritas ni de secuencias estratigráficas, pues en ninguna de ellas se han practicado excavaciones arqueológicas. Tampoco los aparejos constructivos de los edificios que aún se distinguen permiten precisiones al respecto, ya que se trata en general de materiales locales y de técnicas que apenas han experimentado cambios desde la Protohistoria hasta la Edad Contemporánea. Por consiguiente, los datos más fiables proceden de las cerámicas recuperadas en superficie durante las prospecciones sistemáticas - hemos podido estudiar los materiales recogidos en varias de estas alquerías del llano, como el Villar de Hoya Honda, La Graja, Malefatón y la Carrasquilla-, así como de algunos hallazgos casuales de los que existe constancia administrativa o depósito en los museos.

\footnotetext{
${ }^{40}$ Navarro y Jiménez, Siyāsa.
} 
En primer lugar, llama la atención la escasa cantidad de cerámica que se encuentra en superficie, lo que tal vez se deba a que el ajuar de estos campesinos era exiguo, además de pobre. Predominan las formas de cocina: ollas de tipo "valenciano", según definió A. Bazzana, así como cazuelas y marmitas. Las ollas presentan superficie espatulada y cocción reductora; cuerpo globular y un cuello alto y estriado que, por su frecuencia, acaba siendo un motivo identificativo de la adscripción cultural de los yacimientos de la comarca (fig. $10, \mathrm{n}^{\mathrm{o}} 2$ y 5 ; fig. $11, \mathrm{n}^{\mathrm{o}}$ 1 y 4). En segundo lugar están los recipientes para contener líquidos, especialmente jarros, jarras y jarritas. Las jarras suelen presentar decoración pintada, con gruesas líneas verticales paralelas de óxido de manganeso. Entre las jarritas, menos abundantes, destacan las que están decoradas mediante óxido de hierro con motivos en bandas de flores de loto y metopas (fig. 10, $\mathrm{n}^{\mathrm{o}} 7$ ). Destaca, finalmente, la presencia de restos de ataifores con decoración en verde y manganeso y marrón sobre melado (fig. 10, $\mathrm{n}^{\mathrm{o}}$ 1, 3, 4 y 8). Suelen presentar labio recto o ligeramente exvasado y pie relativamente bajo y ancho. Los temas decorativos son difíciles de identificar debido al estado de conservación de los restos, aunque se distinguen motivos geométricos y epigráficos; por ejemplo el nudo de Salomón, en verde y manganeso, que aparece como motivo central en varios ejemplares. Algunos fragmentos informes de ataifores o jofainas presentan decoración vidriada de ovas marrones sobre fondo melado. Finalmente, se identificaron también diferentes restos de redomas, con cubierta vítrea monocroma en verde y tonos azulados, que completan el escaso panorama de vajilla de cierta calidad en estos yacimientos rurales. Aunque en reducido número, también se documentan, especialmente en Mompichel, algunos candiles de piquera y disco. En resumen, los materiales cerámicos recuperados hasta la fecha presentan formas y decoraciones que están bien documentados en contextos surestinos análogos al nivel de abandono de Madīnat al-Zahrā'; fechables, por consiguiente, a comienzos del siglo $\mathrm{XI}$, por ejemplo el nivel reciente del ribāt de Guardamar ${ }^{41} \mathrm{y}$ el Castellar de Alcoy ${ }^{42}$, así como en sendos alfares de Elche ${ }^{43}$ y de Murcia ${ }^{44}$.

${ }^{41}$ Menéndez, "La cerámica de la Rábita Califal".

${ }^{42}$ Pérez Botí, "La caracterización de la cerámica", pp. 59-60 y fig. 6.

${ }^{43}$ Azuar y Menéndez, "El alfar islámico de Elche".

${ }^{44}$ Muñoz y Castaño, "El alfar islámico". 

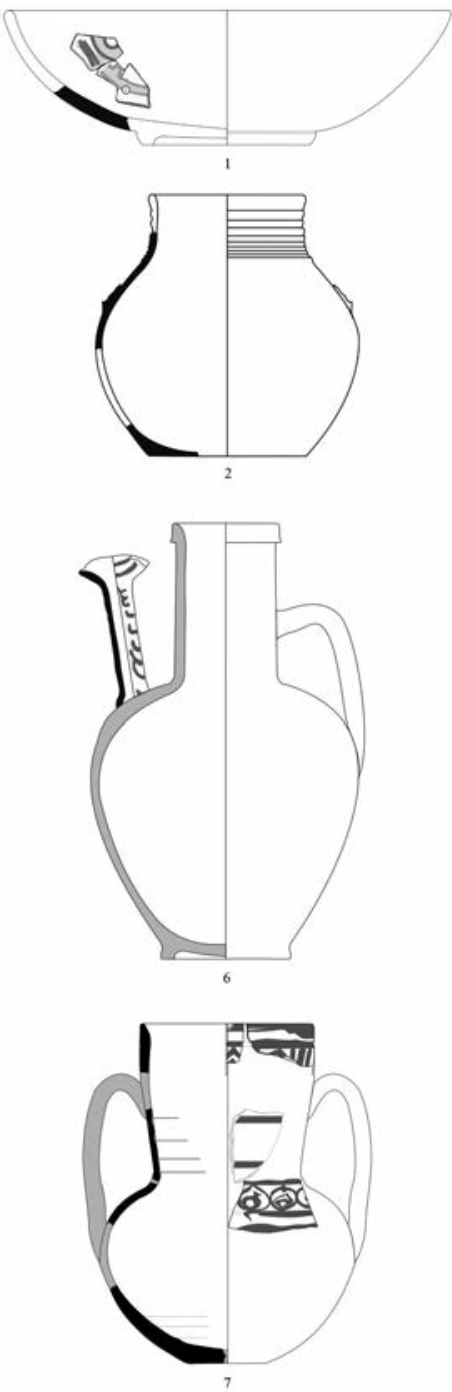
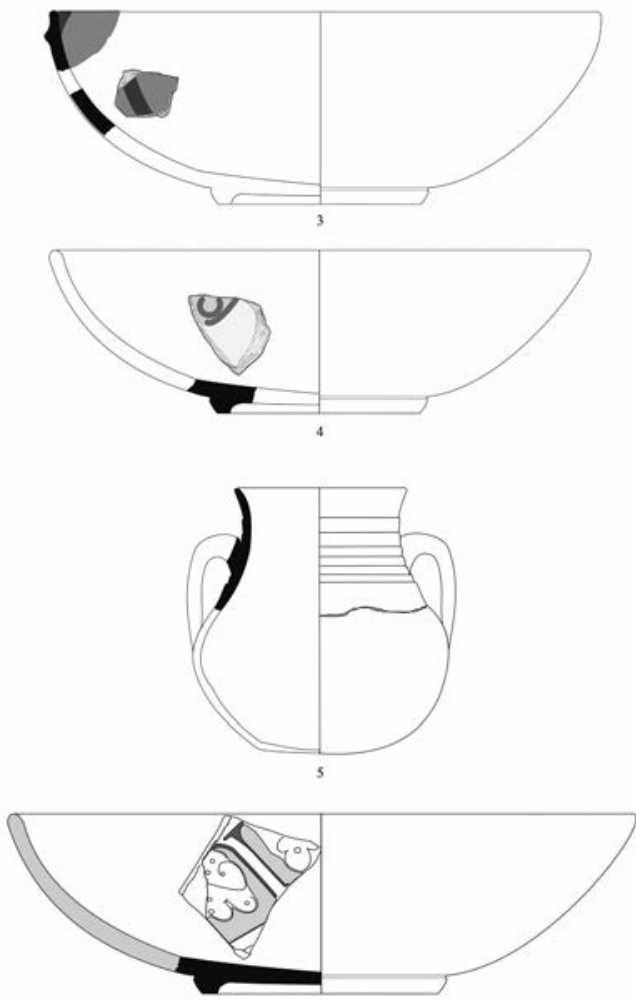

8
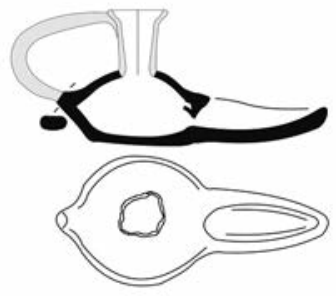

$2-3 \mathrm{~cm}$

Fig. 10. Alquería de Tobillos (Alpera) 1, ataifor de fondo blanco y decoración en verde y morado; 2, olla de cuello estriado. Alquería del Bancal de la Tinaja (Bonete) 3, ataifor melado con decoración de alcafoll; 4, ataifor de fondo blanco y decoración en verde y morado; 5, olla de cuello estriado. Ayna, 6, Jarro. Alquería del Cerrico de don Felipe (Montealegre del Castillo) 7, jarrita. Cerro de Mompichel o de la Tinaja (Chinchilla) 8, ataifor de fondo blanco y decoración en verde y morado; 9, candil de piquera. 


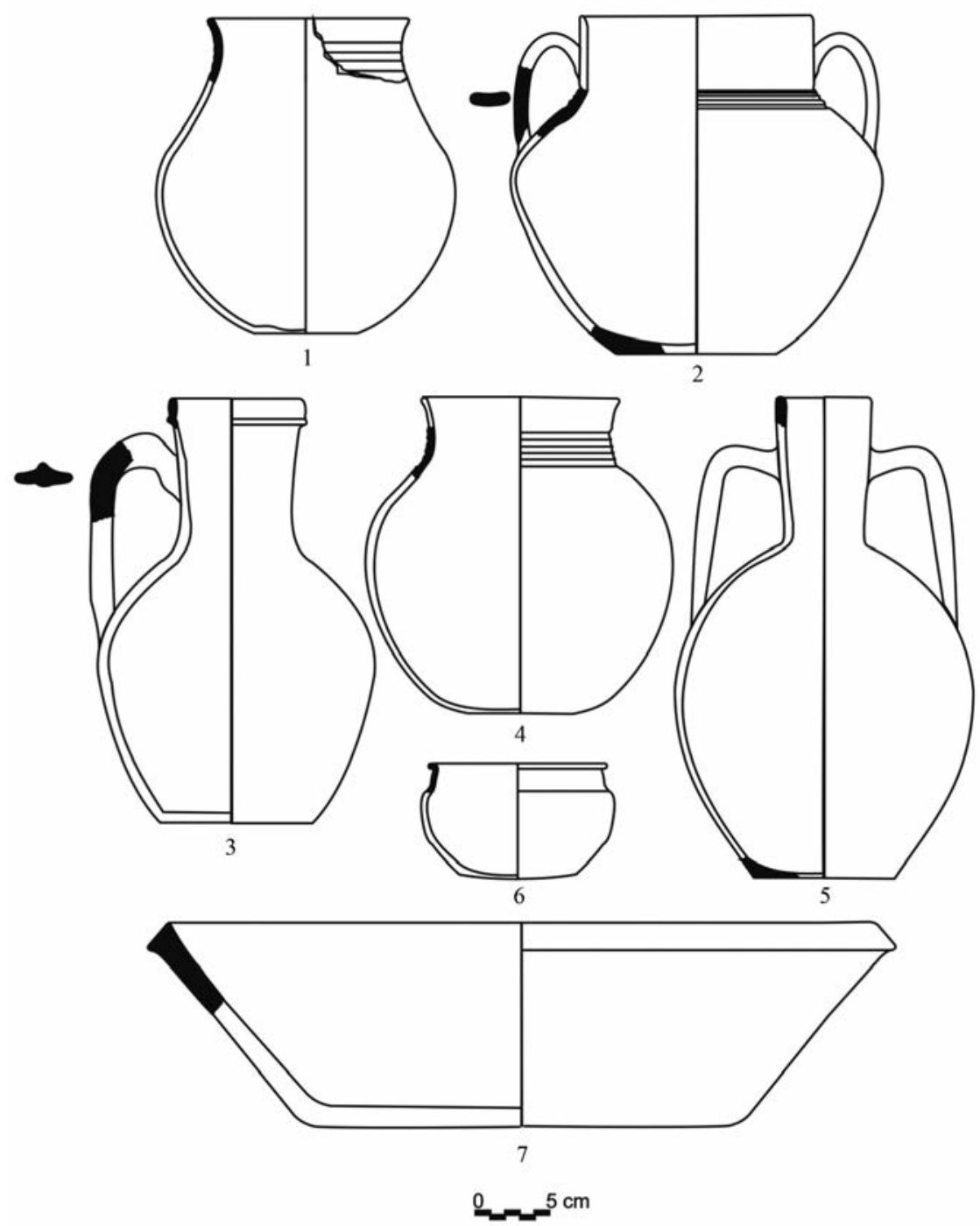

Fig. 11. Alquería del Villar de Hoya Honda (Higueruela). 1, 2, y 4 marmita, 3 jarro, 5 jarra, 6 cazuela y 7 alcadafe. 
En el caso de la alquería del Bancal de la Tinaja, junto a los restos cerámicos se halló una ocultación de dirhems de vellón de la taifa de Valencia ${ }^{45}$, acuñados bajo el mandato de 'Abd al-'Azīz al-Manșūr b. 'Abd al-Raḥmān al-Nāṣir b. Abū 'Amir, entre el 1026 y el 1060, en el 448 y 449 de la Hégira, que confirman la cronología proporcionada por la cerámica, según la cual la ocupación estable se remontaría a fines del siglo $\mathrm{X}$ o la primera mitad del siglo $\mathrm{XI}^{46}$.

Muchos de estos yacimientos tendrán continuidad hasta la conquista cristiana y aportan materiales cerámicos de los periodos almorávide y almohade, como ataifores de labios engrosados y pie anular alto, decorados de forma monocroma, alcafoll y cuerda seca parcial y total, al igual que las tapaderas y candiles, tinajas de paredes estampilladas, ollas, cazuelas y alcadafes y jarras, jarritas con decoraciones propias de estos momentos. De cualquier modo, en todos los casos con la conquista, o quizás con la revuelta mudéjar de 1264, estas alquerías quedan abandonadas, tal y como demuestra el registro cerámico, en el que faltan las producciones características del siglo XIV como los verdes y morados de Paterna.

En resumen, el ajuar cerámico recuperado es modesto cuantitativa y cualitativamente: abundan sobre todo las ollas mientras que son escasas otras piezas relativamente comunes en conjuntos contemporáneos, como por ejemplo la vajilla de mesa vidriada. Gracias a los hallazgos muebles, especialmente a la cerámica, parece posible suponer, a falta de excavaciones arqueológicas, que estos asentamientos surgieron hacia la primera mitad del siglo XI y fueron, en general, abandonados con motivo de la conquista en el segundo tercio del siglo XIII.

\section{Las actividades productivas}

Aunque carecemos de datos arqueológicos o textuales acerca de la actividad productiva de estas alquerías del secano, sabemos que los cortijos y aldeas que en siglos posteriores se desarrollaron en la zona, llegando a emplazarse junto a los restos abandonados de las antiguas bes II".

${ }^{45}$ Sáenz y Vidal, "Hallazgos hispanoárabes"; Sáenz y Vidal, "Hallazgos hispanoára-

${ }^{46}$ Simón, "El poblamiento islámico en el Corredor de Almansa". 
alquerías, tuvieron como principal actividad económica la ganadería de ovejas y cabras. Ésta se complementaba con una serie de bancales de escasa extensión dedicados a los cultivos de la triada mediterránea, junto con los almendros, en una producción claramente de autoconsumo, los excedentes solo podían provenir del ganado, ya fuera como carne o como productos secundarios: leche y derivados, cuero y, muy especialmente, lana.

La mayoría de las alquerías estudiadas están situadas lo más próximo posible a las seculares rutas pecuarias que cruzan la comarca y que conocemos por la documentación posterior a la conquista. Un gran número de ellas, especialmente en el sector oriental de la provincia, se emplazan en las proximidades de lo que posteriormente será la Cañada de los Serranos. En el caso de las alquerías de la zona occidental de la provincia se sitúan en las inmediaciones del ramal de dicha cañada que llega a la Cañada Real de Andalucía. La Cañada de los Serranos ya era, al parecer, empleada en época islámica, quizás en trayectos más locales o comarcales, pero claramente en relación con las necesidades de pastos a lo largo de las diferentes estaciones del año. Estas vías discurren por zonas cuyo paisaje ha propiciado la explotación ganadera secular, tanto para cabañas locales o trasterminantes como para ganados trashumantes de media y larga distancia. A partir de la conquista cristiana de la zona, las cañadas, veredas o coladas quedarán configuradas tal y como las conocemos.

La vinculación de las alquerías en altura con la ganadería es aún más evidente, pues por su elevada localización se encuentran alejadas de las tradicionales zonas de cultivo, salvo algunos reducidos espacios abiertos en la cabecera de barranqueras. Se sitúan en lugares que económicamente han estado orientados a la ganadería y al aprovechamiento de los pastos de altura, ampliamente utilizados hasta mediados del siglo pasado al conservar una mayor humedad hasta bien entrado el estío. Prueba de este secular uso son los corrales que todavía se distribuyen en las solanas de las laderas de las elevaciones, generalmente cercanos a manantiales donde abrevar el ganado, en zonas alejadas de los espacios de cultivo y escasas en vegetación de arbolado, en donde predomina el estepar y el monte bajo. También la mayoría de estas alquerías se emplazan junto a cañadas, veredas y cordeles ganaderos, o muy cerca de ellos, que se han utilizado hasta hace menos de un siglo y que todavía hoy en día se encuentran amojonados o señalados en las cartografías específicas. 
A pesar de la indigencia de los estudios sobre la ganadería en alAndalus, existen pruebas que demuestran la existencia del pastoreo transterminante e incluso de la trashumancia ${ }^{47}$, lo que no significa que esta actividad estuviera organizada como lo estuvo en la Castilla bajomedieval. Entre las sentencias jurídicas del cadí 'Iyād hay una muy interesante pues hace referencia a un grupo de pastores que moraban en una alquería (qarya) junto con sus familias y con otros que debían de ser agricultores; la cuestión es que esos pastores pretendían no participar en el pago del sueldo del imām de la mezquita, al igual que el resto de los habitantes censados, porque afirmaban que no permanecían en la alquería más que unos pocos días pues el resto del tiempo lo pasaban fuera con sus ganados ${ }^{48}$. No se precisa el tiempo que pastores estaban fuera, pero, dado que el imām dirigía la oración cada viernes, la queja no se entendería si únicamente se ausentaban algunos días, sólo podía sustentarse si los periodos abarcaban varias semanas o incluso meses.

La ganadería ovina de estos asentamientos pudo abastecer a los talleres para la elaboración de paños de la región, industria que también existió en época cristiana ${ }^{49}$. Los textos árabes insisten en las manufacturas derivadas de la lana que se producían aquí y que eran objeto de comercio. A mediados del siglo XII, al-Idrīsī destaca a Chinchilla, junto con Cuenca, como centro productor de tapices o mantas (wața $)$ de lana "que no podrían imitarse, circunstancia que depende de la calidad del aire y de las aguas" ${ }^{\prime 50}$. Esta noticia aparece también en la obra del geógrafo e historiador oriental al-Ḥimyarī (s. XV), quien refiere que "de esta localidad reciben el nombre algunos tapices llamados «de Chinchilla», pues es en ella donde se fabrican" ${ }^{51}$. Más adelante confirma la noticia al hacer referencia a Iniesta, pues dice que ésta es un "castillo de al-Andalus a unas dos jornadas de Chinchilla, la localidad donde se fabrican tapices" 52 . A partir de estas referencias, es posible suponer que sea precisamente Chinchilla el lugar cercano a Tudmīr en donde, en el siglo XI, al-'Ud́rī señalaba la fabricación de "maravillosos talleres de alfombras y tapices o cobertores" $"$. Por otra parte, el comercio de las

\footnotetext{
${ }^{47}$ Véase, por ejemplo, Cara, "El ámbito económico del pastoralismo andalusí”.

${ }^{48}$ Ibn 'Iyāḍ, Madahib al-ḥukkām, trad. Serrano, p. 74.

${ }^{49}$ Pretel, Chinchilla medieval; González, La industria de Chinchilla en el siglo XV.

${ }^{50}$ al-Idrīsī, Geografía, p. 185.

${ }^{51}$ al-Himyarī, Kitāb al-Rawd, p. 116.

52 al-Himyarī, Kitāb al-Rawḍ, p. 197.

53 al-'Ud̆rī, Tarṣī', p. 9.
} 
alfombras andalusíes durante los siglos XI y XII hacia Oriente, Túnez y Egipto, así como hacia los reinos cristianos del norte, está bien documentado en las fuentes textuales ${ }^{54}$. Parece lógico poner en relación el desarrollo de la explotación ganadera en la comarca que venimos examinando con el de la industria lanera de orientación comercial en Chinchilla pues, dado que no existen otros condicionantes que lo justifiquen como podría ocurrir si estuviéramos ante un activo puerto marítimo o una gran medina, cabe suponer que el desarrollo de tales manufacturas en esta localidad y en alguna otra ciudad de la Meseta Central se originó por la proximidad a la materia prima.

En resumen, teniendo en cuenta los aspectos antropológicos, el emplazamiento de las alquerías junto a vías pecuarias tradicionales, las características de los patios-corrales asociados a las viviendas y la presencia de lo que parecen rediles comunitarios en algunos de los asentamientos, creemos que, al igual que en épocas más recientes, las comunidades medievales de esta comarca debieron de basar su sustento en la agricultura de secano y en la ganadería, especialmente ovina y caprina, lo que conviene con las condiciones geográficas de la región y también con la información, ciertamente escasa, que proporcionan las fuentes escritas. Las huertas se limitaron a los estrechos márgenes de vegas abastecidas por manantiales, siendo la de Alpera la de mayor tamaño de la comarca, con $6 \mathrm{~km}$ de largo y unos $70 \mathrm{~m}$ de anchura media a ambos lados de un cauce cuyo exiguo caudal, junto a los condicionantes orográficos, no permitieron desvíos o canalizaciones mediante paradas o azudes, ni elevaciones con norias y aceñas.

\section{Discusión y conclusiones}

A partir de los datos obtenidos, podemos resumir las principales características del conjunto de asentamientos que hemos venido examinando:

- Se trata de localidades modestas, que albergaban entre 15 y 50 edificios, como término medio, dispersos o reunidos en proto-manzanas entre las que aparecen espacios de circulación irregulares.

${ }^{54}$ Constable, Comercio y comerciantes, pp. 214 y 215. 
- La mayoría se sitúan en zonas llanas o levemente onduladas, en donde se localiza la mayor densidad de asentamientos, aunque existe también un grupo ubicado en las laderas de cerros y colinas.

- La arquitectura doméstica es de tipo rural, con dependencias escasas y poco caracterizadas en cuanto a su función, abiertas a rediles que cumplen la función de patio. No existen viviendas especialmente ricas, ni mucho menos palatinas. La modestia de la arquitectura concuerda con la del ajuar cerámico.

- No se distinguen estructuras defensivas comunitarias, a lo sumo alguna cerca perimetral o alguna torre en las emplazadas en el sector sureste del área estudiada, ni los emplazamientos elegidos son favorables en este sentido. Tampoco se han hallado restos de otros edificios de carácter militar o aristocrático.

- Están ubicadas en zonas carentes de recursos hídricos, por lo que su principal recurso productivo no debió de ser la agricultura irrigada, inexistente o insignificante, sino precisamente la ganadería menor - lo que conviene con el tipo de vivienda documentado-, la agricultura de secano y la explotación de áreas incultas, dado que en la región no existían recursos mineros, forestales o de otro tipo. A nivel agrícola las tierras que circundan estas alquerías solo son aptas, inclusive hoy en día, para el cultivo rotativo de cereales y leguminosas, mientras que el ámbito de regadío se limita al fondo de alguna estrecha vega o barranquera, protegida de los vientos dominantes, cuya producción debió de ser muy limitada. Además, la agricultura extensiva, que conlleva rotaciones para el barbecho que liberan periódicamente de cultivos extensos espacios, es la solución productiva más apropiada para practicarla en asociación con la ganadería

- Los indicios arqueológicos y toponímicos parece apuntar a que los moradores de estos asentamientos no eran grupos clánicos de carácter segmentario, sino familias de tipo "nuclear", modelo éste que parece asociarse con la agricultura de secano según Pierre Toubert ${ }^{55}$.

- Parecen haberse fundado mayoritariamente en el siglo XI, abandonándose con motivo de la conquista castellana a mediados del

${ }^{55}$ Toubert, "Le moment carolingien". 
s. XIII, de manera que la mayoría de ellas nunca más han vuelto a ser pobladas.

Para comprender las causas que explican el poblamiento que venimos examinando creemos necesario atender al contexto económico y social en el que surgió y se desarrolló.

A partir de una fecha imprecisa, aproximadamente hacia la segunda mitad del siglo $\mathrm{X}$, arranca en al-Andalus un proceso de crecimiento demográfico - expresado en el desarrollo de los núcleos de población-, y un despegue productivo que Lucie Bolens denominó la "revolución agrícola andalusí del s. XI" ${ }^{56}$, uno de cuyos síntomas habría sido la proliferación en el siglo XI, de los tratados geopónicos sobre métodos, técnicas de cultivo y producción agrícola. Este proceso compartiría cronología y muchas de sus características con el que tuvo lugar en Europa occidental entre los siglos X y XIV (hasta la crisis demográfica provocadas por las epidemias de peste negra), conocido en la historiografía como "la gran expansión", o como la "revolución comercial" pues también se vio acompañado por un notable aumento de los intercambios mercantiles y de la producción para el mercado ${ }^{57}$. Pierre Guichard demostró que algunas de las pocas referencias textuales con que contamos acerca del medio agrario en el siglo XI, obligan a matizar la optimista interpretación de Bolens ${ }^{58}$; en este sentido, Ibn Ḥayyān explica que los dos copríncipes eslavos de Valencia, Mubārak y Muzaffar, percibieron cuantiosos impuestos [harāğ] que "recaudaban con el mayor rigor de todas las categorías de la población, hasta el punto que la situación de sus súbditos se degradó. Las gentes emigraron unas tras otras de las regiones que ocupaban, las cuales, a fin de cuentas, se arruinaron". Esta presión fiscal insoportable obligó a los campesinos a dejar sus lugares de origen: "la gente no pudo hacerle frente sino emigrando de sus casas y abandonando sus alquerías [qurā]". La imposibilidad de afrontar las cargas impositivas y las deudas dio lugar a la expropiación de las fincas, que pasaron a manos de la aristocracia terrateniente: “... se apropiaban los pueblos cuya gente había emigrado para hacer de

${ }^{56}$ Bolens, Les méthodes culturales au Moyen Âge; Bolens, La révolution agricole. La supuesta incidencia de la descentralización sobre la actividad agrícola ya fue criticada por: Glick, Islamic and Christian Spain, p. 69.

${ }^{57}$ Lopez, La revolución comercial, pp. 15-17 y ss.

${ }^{58}$ Guichard, "Crecimiento urbano y sociedad rural", pp. 164 y ss. 
ellos explotaciones particulares [diya mustahlasa]". Cuando los notables se habían adueñado de las alquerías y las habían transformado en dominios privados o aldeas, gracias al peso irresistible de la fiscalidad sobre los campesinos, las ponían en cultivo mediante aparceros contratados, que a veces eran los antiguos propietarios de esas mismas tierras $^{59}$; "eso fue lo que hicieron la mayor parte de los rebeldes que se adueñaron de las regiones del Andalus o se sublevaron en sus confines" 60 .

El fenómeno descrito por Ibn Ḥayyān responde a pautas analizadas desde la antropología comparada, pues en las sociedades agrarias avanzadas como la andalusí, el incremento de los beneficios que pudiera reportar la actividad agrícola debido al aumento de la demanda, siempre se ha visto acompañado por la presión de las élites para controlar la producción ${ }^{61}$. En las sociedades agrarias comercializadas la oligarquía no se conformaba con presionar para hacerse con el excedente del producto campesino, sino que pretendía arrebatar la tierra al campesinado $^{62}$. Según este modelo, el aumento de los impuestos, favorecido por el desarrollo de los sistemas monetarios, desembocaba en el endeudamiento y la expropiación de la tierra en la medida en que los deudores se volvieran insolventes y se extinguiera el derecho de redimir hipotecas.

En este proceso se produjo un movimiento demográfico que afectó a los campesinos desposeídos y que apenas ha dejado huella en las fuentes escritas conservadas. Ibn Ḥayyān se refiere indirectamente a ello cuando explica que los notables "se apropiaban de los pueblos cuya gente había emigrado para hacer de ellos explotaciones particulares". Un destino obvio de los campesinos desposeídos fueron las ciudades, lo que podría explicar, más que el crecimiento vegetativo de la población, su desarrollo general durante el siglo $\mathrm{XI}^{63}$. Así lo narra una elocuente fábula del proceso de comercialización transmitida por Ibn al-Jațīb, que habría que situar en la Murcia de mediados del siglo XII, en un contexto socioeconómico caracterizado por una presión fiscal desmesurada. Refiere la historia de un súbdito de Ibn Mardanī̌s, que

${ }^{59}$ Guichard, "Crecimiento urbano y sociedad rural", p. 171.

${ }^{60}$ Guichard, "Crecimiento urbano y sociedad rural", p. 160.

${ }^{61}$ Lenski, Poder y privilegio, pp. 201-308.

${ }^{62}$ Kautsky, The Politics of Aristocratic Empires.

${ }^{63}$ Mazzoli-Guintard, Villes d'al-Andalus, p. 187. 
tenía en los alrededores de Játiva "una pequeña finca de la que vivía, pero los impuestos superaron sus ganancias y huyó a Murcia, aunque Ibn Mardanīš tenía establecido que quien huyese ante el enemigo, se le confiscarían los bienes para el tesoro. El hombre de Xátiva contaba: cuando llegué a Murcia, huido de mi patria, me coloqué en la construcción..." ${ }^{94}$. El texto prosigue relatando las tribulaciones del personaje en la ciudad, perseguido por toda clase de cobradores de impuestos, aunque para nosotros ahora basta con este arranque del relato, puesto que precisamente narra a un público que estaría familiarizado con la situación, cómo un campesino podía perder su tierra por causa de la presión fiscal, viéndose forzado a emigrar a la ciudad para convertirse en obrero de escasa cualificación. Por consiguiente, el crecimiento urbano se vería propiciado por dos circunstancias relacionadas entre sí: por un lado, el enriquecimiento por las rentas agrícolas de unos aristócratas terratenientes que moran en la ciudad y que emprenden gastos suntuarios creando una demanda que da lugar a la expansión del artesanado; por otro, la inmigración de la población campesina que se traslada a la ciudad para emplearse como obreros asalariados de ese artesanado en desarrollo, empujada por la pérdida de sus tierras a mano de los notables.

Pero el traslado a las urbes era una opción arriesgada que suponía abandonar la relativa seguridad del sustento que proporcionaba el campo por el albur del trabajo por cuenta de otros; de hecho, según la fábula anterior, la decisión de emigrar no mejoró la calidad de vida de su protagonista, al contrario, enlazó una serie de penalidades hasta terminar preso y sujeto a trabajos forzados. También desde el punto de vista antropológico, Arnold concluye que en las sociedades preindustriales la fabricación de cerámica y otros oficios son una elección secundaria a la que recurren personas que poseen tierras insuficientes, de baja calidad, o que carecen de ella, pues mientras que la agricultura proporciona alimento directamente a una familia, la producción artesanal no lo hace, sino que exige un trabajo adicional y riesgos mayores $^{65}$.

Por todo ello, los contextos históricos de expansión de la agricultura comercial y presión sobre el estamento campesino se suelen ver acom-

${ }^{64}$ Epalza y Rubiera, "La sofra (sujra)", p. 34.

${ }^{65}$ Arnold, Ceramic Theory, p. 193. 
pañados, además de por el crecimiento urbano, por procesos de colonización de nuevas tierras ${ }^{66}$. Durante el siglo XI, por ejemplo, en Europa occidental, como consecuencia del crecimiento demográfico y el aumento de la producción con destino al mercado, los señores terratenientes orientaron la demanda de tierra de cultivo por parte de los campesinos hacia la colonización de zonas de bosque, de monte bajo y terrenos pantanosos. La puesta en producción de nuevas tierras en alAndalus debió de operar bajo mecanismos sensiblemente diferentes a los de las sociedades señoriales europeas. La ley islámica favorece la creación de propiedad mediante la vivificación de nuevas tierras, distinguiendo entre las de regadío conocidas como mamlūka o apropiadas $^{67}$, y las que podían ser puestas en cultivo por cualquiera, llamadas tierras muertas o mawāt, lo que con respecto a la propiedad significa tierra sin uso y sin propietario. La vivificación de tierras en al-Andalus podía producirse de manera comunitaria por la llegada de nuevos grupos tribales a la península o por la escisión de otros ya asentados; o bien, de manera particular, por agricultores modestos o por grandes terratenientes. En el caso que nos ocupa, creemos que se puede descartar la colonización por parte de grupos gentilicios teniendo en cuenta lo que se puede deducir de la toponimia y de las fechas avanzadas que venimos manejando para los asentamientos, pues la sociedad tribal inició su declive a comienzos del siglo $X$, cuando se inició una transición compleja que finalizó con el triunfo del Estado omeya y la imposición de la formación social islámica caracterizada por la hegemonía de lo privado y del mundo urbano ${ }^{68}$. Tampoco las características geográficas de la región, en la que la práctica de la agricultura hidráulica estaba muy limitada, eran favorables al modelo de espacio productivo y área de residencia campesina por el que optaban preferentemente los grupos clánicos para garantizar su reproducción social ${ }^{69}$. Por otra parte, la ausencia de restos de edificios de tipo aristocrático, nos lleva a pensar que no estamos ante almunias o rahales pertenecientes al patriciado urbano, por lo que nos inclinamos por pensar que estaban habitadas por modestos agricultores particulares no organizados mediante lazos tri-

${ }^{66}$ Hilton, Siervos liberados, pp. 51 y ss.

${ }^{67}$ Akbar, Crisis, pp. 27-32.

${ }^{68}$ Acién, "Poblamiento y fortificación", p. 142.

${ }^{69}$ Barceló, Kirchner y Navarro, El agua que no duerme, pp. 62, 63 y 76. 
bales; en definitiva, el modelo de campesino más común en al-Andalus en este momento avanzado, a juzgar por los indicios que se pueden extraer de las fuentes escritas ${ }^{70}$, aunque debemos admitir que no existen pruebas concluyentes al respecto y lo expuesto no es más que una hipótesis de trabajo.

En resumen, el poblamiento y colonización de tierras desfavorecidas como las de La Mancha oriental durante este periodo ha de enmarcarse en un contexto de expansión comercial y agraria, enraizada en un despegue demográfico generalizado. El aumento de la demanda de alimentos incrementó la rentabilidad comercial de la agricultura y ello conllevó la presión de las oligarquías urbanas para hacerse con la tierra, arrebatándosela en algunos casos a las comunidades campesinas de las alquerías, como relata Ibn Ḥayyān, o estableciéndose en áreas menos favorables pero desocupadas, como sucede con las almunias del Pla de Lérida $^{71}$. Las alternativas de los campesinos desposeídos parecen reducirse al arrendamiento de tierras; al trabajo como jornaleros; a la emigración a las ciudades en donde engrosar las clases inferiores de artesanos y asalariados; o, tal vez, a la vivificación de zonas esteparias pero aún libres como sería el caso que hemos examinado. Estas tierras solo permitían practicar una agricultura pobre de secano, aunque también una actividad ganadera que se benefició del desarrollo de las manufacturas textiles en esa comarca y su comercio. En nuestra opinión, todos estos factores debieron de contribuir al proceso que hemos examinado, seguramente junto con otros que no hemos identificado y que serán puestos de manifiesto por futuros estudios.

\section{Bibliografía}

Acién Almansa, Manuel, "Poblamiento y fortificación en el sur de al-Andalus.

La formación de un país de hușūn", III Congreso de Arqueología Medieval Española, Oviedo, Universidad de Oviedo, 1988, t. I, pp. 135-150.

Akbar, Jamel, Crisis in the Built Environment. The Case of the Muslim City, Singapur, Concept Media, 1988.

${ }^{70}$ Por ejemplo, a partir del análisis de las sentencias relacionadas con la actividad judicial del cadí 'Iyāụ (1083-1149), Delfina Serrano concluye que "la propiedad es individual en la práctica totalidad de los casos" (Ibn 'Iyāọ, Madahib al-hukkām, pp. 56, 62 y 63).

${ }^{71}$ Brufal, "La Lleida de secano". 
Arnold, Dean, Ceramic Theory and Cultural Process, Cambridge, Cambridge University Press, 1985.

Azuar Ruiz, Rafael y Menéndez Fueyo, José Luis, "El alfar islámico de Elche (Alicante) (siglos XI-XIII)”, II Congreso de Arqueología Penínsular, vol. 4, Zamora, Rei Alfonso Enriques, 1999, pp. 679-670.

Ballesteros Arias, Paula, et al., "Por una arqueología agraria de las sociedades medievales hispánicas. Propuesta de un protocolo de investigación", en H. Kirchner (ed.), Por una arqueología agraria. Perspectivas de investigación sobre espacios de cultivo en las sociedades medievales hispánicas, Oxford, Archaeopress, 2010, pp. 185-202.

Barceló, Miquel et al., Arqueología medieval. En las afueras del "medievalismo”, Barcelona, Crítica, 1988.

Barceló, Miquel, "El diseño de los espacios irrigados en Al-Andalus: un enunciado de principios generales", El agua en zonas áridas: Arqueología e Historia. I Coloquio de historia y medio físico, vol. I, Almería, Instituto de Estudios Almerienses, 1989, pp. XV-XLXI.

Barceló, Miquel, Kirchner, Helena y Navarro, Carmen, El agua que no duerme. Fundamentos de la arqueología hidráulica andalusí, Granada, El legado andalusí, 1996.

Bazzana, André y Guichard, Pierre, "Irrigation et société dans l'Espagne orientale au Moyen Age", L'homme et l'eau en Méditerranée et au Proche-Orient. I. Séminaire de recherche 1979-1980, Lyon, GIS-Maison de l'Orient, 1981, pp. 115-140.

Bolens, Lucie, Les méthodes culturales au Moyen Âge d'après les traités d'agronomie andalous. Tradition et technique, Ginebra, Tesis doctoral inédita, 1974.

Bolens, Lucie, "La révolution agricole andalouse du XI' siècle", Studia Islamica, 47 (1978), pp. 121-141.

Brufal, Jesús, "La Lleida de secano en los siglos XI-XIII: nueva interpretación del territorio", en Malpica, A. (ed.) Análisis de los paisajes históricos. De alAndalus a la sociedad feudal, Granada, Alhulia, 2009, pp. 241-265.

Cara Barrionuevo, Lorenzo, "El ámbito económico del pastoralismo andalusí. Grandes aljibes ganaderos en la provincia de Almería", El agua en zonas áridas: Arqueología e Historia: actas del I Coloquio de Historia y medio físico, Almería, Instituto de Estudios Almerienses, 1989, pp. 633-653.

Cara Barrionuevo, Lorenzo, "Huellas de pastores: observando los paisajes ganaderos de los «extremos» granadinos", en Malpica, A. (ed.) Análisis de Los Paisajes Históricos. De Al-Ándalus a La Sociedad Feudal, Granada, Alhulia, 2009, pp. 169-202.

Cebrián Abellán, Aurelio y Cano Valero, José, (eds.), Relaciones topográficas de los pueblos del Reino de Murcia, Murcia, Universidad de Murcia, 1992.

Chavarría Vargas, Juan Antonio, Cuando Castilla-La Mancha era AlAndalus: geografia y toponimia, Ciudad Real, Almud, 2011. 
Constable, Olivia Remie, Comercio y comerciantes en la España musulmana, Barcelona, Omega, 1997.

Corriente, Federico, "Huellas lingüísticas de secanos y regadíos en el occidente islámico", Els espais de secà. IV Curs internacional d'Arqueologia Medieval, Lérida, Pagès, 2011, pp. 19-29.

Cressier, Patrice, "Fonction et évolution du réseau castral en Andalousie orientale: le cas de 1'Alpuijarra", Castrum 3. Guerre, fortification et hábitat dans le monde méditerranéen au Moyen Âge, Madrid-Roma, Casa de VelázquezÉcole Française de Rome, 1988, pp. 123-134.

De Epalza, Míkel y Rubiera, Ma Jesús, "La sofra (sujra) en el Sharq Al-Andalus antes de la conquista catalano-aragonesa", Sharq Al-Andalus, 3 (1986), pp. 33-38.

García Gandía, José Ramón, Llorens Campello, Sergio y Pérez Botí, Germán, “L' Almisserà: territorio castral y espacio rural en época islámica”, en F. J. Jover Maestre y C. Navarro Poveda (eds.), De la medina a la vila. II Jornadas de Arqueología Medieval, Alicante, Diputación Provincial de Alicante-Centre d'Estudis Locals del Vinalopó, 2004, pp. 83-105.

García-García, Marcos y Moreno-García, Marta, "De huertas y rebaños: perspectivas históricas y ecológicas sobre el papel de la ganadería en la agricultura andalusí", III Seminario Anual de la Sociedad Española de Historia Agraria (SEHA), Madrid, 28 de noviembre de 2014. [En línea], http://seha.info/8/3 seminario/SEHA3 seminario_MarcosGarcia-GarciayMartaMorenoGarcia.docx [consulta: 07/07/2016]

García-Saúco Beléndez, Luis Guillermo y Santamaría Conde, Alfonso, "Unos baños árabes en Chinchilla", I Congreso de Historia de Albacete, vol. I, Albacete, Instituto de Estudios Albacetenses, 1986, pp. 389-397.

Glick, Thomas, Irrigation and Society in Medieval Valencia, Cambridge, Cambridge University Press, 1970.

Glick, Thomas, Islamic and Christian Spain in the Early Middle Ages, Princeton, Princeton University Press, 1979.

González Arce, José Damián, La industria de Chinchilla en el siglo XV, Albacete, Instituto de Estudios Albacetenses, 1993.

Guichard, Pierre, "Crecimiento urbano y sociedad rural en Valencia a principios de la época de los reinos de taifas (siglo XI después de J. C.). Traducción y comentario de un texto de Ibn Hayyān", Estudios sobre Historia Medieval, Valencia, Institució Valenciana d'Estudis i Investigació, 1987, pp. 153-174.

Gutiérrez Lloret, Sonia, “Casa y casas: reflexiones arqueológicas sobre la lectura social del espacio doméstico medieval”, en $\mathrm{M}^{\mathrm{a}}$ Elena Díez y J. Navarro (eds.) La casa medieval en la península ibérica, Madrid, Sílex, 2015, pp. 17-48.

Hernández Carrión, Emiliano y Simón García, José Luis, El castillo de Jumilla. Historia de un Centinela, Jumilla, Museo Municipal Jerónimo Molina, 2015. 
Hilton, Rodney, Siervos liberados. Los movimientos campesinos medievales y el levantamiento inglés de 1381, Madrid, Siglo XXI, 1985.

Himyarī (al-), Kitāb al-Raw d al-mi 'țār, ed. y trad. francesa por E. Lévi-Provençal, La Péninsule Iberique au Moyen-Âge, Leiden, Brill, 1938.

Ibn 'Iyāḍ, Madahib al-ḥukkām fĩ nawaz̄il al-ahkām (La actuación de los jueces en los procesos judiciales), trad. y est. Delfina Serrano, Madrid, CSIC, 1998.

Al-Idrīsī, Nuzhat al muštaq, edición y traducción francesa parciales de R. Dozy y M. J. de Goeje, Description de l'Afrique et de l'Espagne, Leiden, Brill, 1866 (reimpresión 1968).

Al-Idrīsī, Geografía de España, Valencia, Anubar, 1974.

Jiménez Puertas, Miguel y Carvajal López, José Cristóbal, “Opciones sociotécnicas de regadío y de secano. El caso de la Vega de Granada”, Els espais de secà. IV Curs internacional d'Arqueologia Medieval, Lérida, Pagès, 2011, pp. 51-85.

Kautsky, John H., The Politics of Aristocratic Empires, University of North Carolina Press, Chapel Hill (NC), 1982.

Kirchner, Helena, "Redes de asentamientos andalusíes y espacios irrigados a partir de qanāt(s) en la sierra de Tramuntana de Mallorca: una reconsideración de la construcción del espacio campesino en Mayūrqa”, en H. Kirchner (ed.) Por una arqueología agraria. Perspectivas de investigación sobre espacios de cultivo en las sociedades medievales hispánicas, Oxford, BAR International Series, 2010.

Lenski, Gerhard, Poder y privilegio. Teoría de la estratificación social, Barcelona, Paidós, 1969.

Lopez, Roberto Sabatino, The Commercial Revolution of the Middle Ages 9501350, Nueva York, Prentice Hall Press, 1971; trad. española, La revolución comercial en la Europa Medieval, Barcelona, El Albir, 1981.

Malpica Cuello, Antonio, "La vida agrícola y la ganadería en al-Andalus y en el reino nazarí de Granada”, en R. Marín (coord.) Homenaje al Profesor Dr. D. José Ignacio Fernández de Viana y Vieites, Granada, Universidad de Granada, 2012, pp. 213-228.

Mazzoli-Guintard, Christine, Villes d'al-Andalus. L'Espagne et le Portugal à l'époque musulmane (VIIIe-XVe siècles), Rennes, Presses Universitaires de Rennes, 1996.

Menéndez Fueyo, José Luis, "La cerámica de la Rábita Califal”, El ribāt califal. Excavaciones e investigaciones (1984-1992), Madrid, Casa de Velázquez, 2004, pp. 89-130.

Molina López, Emilio, "La cora de Tudmīr según al- 'Uḍrī (siglo XI). Aportaciones al estudio geográfico-descriptivo del SE peninsular", Cuadernos de Historia del Islam, 4 (1972), vol. monográfico.

Muñoz López, Francisco y Castaño Blázquez, Trinidad, "El alfar islámico de la calle Pedro de la Flor", Verdolay, 5 (1993), pp. 157-169. 
Navarro, Carmen, "Fortificaciones y asentamientos andalusíes en la actual provincia de Albacete: un al-Andalus textualmente casi invisible", en M. Barceló, y P. Toubert, "L'incastellamento» Actes des rencontres de Gérone (26-27 novembre 1992) et de Rome (5-7 mai 1994), Roma, Ecole Française de Rome - Escuela Española de Historia y Arqueología en Roma, 1998, pp. 291-305.

Navarro Palazón, Julio y Jiménez Castillo, Pedro, Siyāsa. Estudio arqueológico del despoblado andalusí (siglos XI-XIII), Murcia, El Legado Andalusí, 2007.

Newfield, Timothy P., "Early Medieval Epizootics and Landscapes of Disease: The Origins and Triggers of European Livestock Pestilences, 400-1000 CE", en Sunhild Kleingartner (ed.), Landscapes and Societies in Medieval Europe East of the Elbe, Toronto, PIMS, 2013, pp. 73-113.

Pérez Botí, Germán, "La caracterización de la cerámica islámica de El Castellar de Alcoi (Alicante) de finales del siglo IX y siglo X: El Horizonte Castellar I', Recerques del Museu d'Alcoi, 22/23 (2014), pp. 53-68.

Pocklington, Robert, “Toponimia Ibérica, Latina y Árabe de la provincia de Albacete", Al-Basit, 55 (2010), pp. 111-167.

Ponce Herrero, Gabino, El Corredor de Almansa: estudio geográfico, Albacete, Instituto de Estudios Albacetenses, 1989.

Pozo Martínez, Indalecio, "La alquería islámica de Villa Vieja (Calasparra, Murcia)", Castrum 6. Maisons et espaces domestiques dans le Monde Méditerranéen au Moyen Âge, Roma-Madrid, 2000, pp. 165-175.

Pretel Marín, Aurelio, Chinchilla medieval, Albacete, Instituto de Estudios Albacetenses, 1992.

Retamero Serralvo, Félix, "Pautes per al l'estudi dels conreus de secà a Alandalús”, en Sabaté, Flocel y Brufal, Jesús (eds.), Els espais de secà. IV Curs internacional d'Arqueologia Medieval, Lérida, Pagès, 2011, pp. 31-49.

Ruiz Molina, Liborio, "Ḥiṣn Yakka. Un castillo rural de Šarq al-Andalus. Siglos XI al XIII. Excavaciones Arqueológicas en el Cerro del Castillo de Yecla (1990-1999)", Revista de Estudios Yeclanos, 10 (2000), vol. monográfico.

Ruiz Molina, Liborio, "Yakka: un castillo de Šarq al-Andalus en los siglos XII y XIII. Aproximación histórica al poblamiento almohade en Yecla (Murcia)", Tudmīr, 1 (2009), pp. 77-138.

Sabaté, Flocel y Brufal, Jesús (eds.), Els espais de secà. IV Curs internacional d'Arqueologia Medieval, Lérida, Pagès, 2011.

Sáenz Díez, Juan Ignacio y Vidal Bardán, José María, "Hallazgos hispanoárabes en el Museo de Albacete", Gaceta Numismática, 80 (1986), pp. 35-42.

Sáenz Díez, Juan Ignacio y Vidal Bardán, José María, "Hallazgos hispanoárabes en el Museo de Albacete II", Gaceta Numismática, 82 (1988), pp. 57-62.

Sánchez Sánchez, José, Geografía de Albacete: factores del desarrollo económico de la provincia y su evolución reciente, Albacete, Instituto de Estudios Albacetenses, 1982. 
Sitjes, Eugènia, "Inventario y tipología de sistemas hidráulicos de al-Andalus", Arqueología Espacial, 26 (2006), pp. 263-291.

Simón García, José Luis, "El poblamiento islámico en el Corredor de Almansa y las tierras de Montearagón: Los andalusíes olvidados", Las raíces de Almansa: desde los orígenes del poblamiento hasta el fin de la Edad Media. XVI Jornadas de Estudios Locales, Almansa, Ayuntamiento de Almansa, 2011.

Simón García, José Luis, Castillos y torres de Albacete, Albacete, Instituto de Estudios Albacetenses "Don Juan Manuel”, 2011.

Simón García, José Luis, "Del ḥiṣn al-Karas al castrum de Alcaraz: una aproximación desde la arqueología", Alcaraz: del Islam al concejo castellano, Alcaraz, Ayuntamiento de Alcaraz-IEA “Don Juan Manuel”, 2013, pp. 55-76.

Simón García, José Luis, "El poblamiento islámico en Albacete. Las alquerías andalusíes del Villar de Hoya Honda y la Graja (Higueruela, Albacete)”, $A l$ Basit, 59 (2014), pp. 191-252.

Simón García, José Luis, "El poblamiento islámico de las tierras de Alcalá del Júcar (siglos VIII al XIII)", Alcalá del Júcar: piedra, tierra, agua y sus gentes, Albacete, Instituto de Estudios Albacetenses "Don Juan Manuel”, 2014, pp. 53-84.

Simón García, José Luis, "Sax, Salinas, Villena y Caudete en el sistema de fortificación de la frontera medieval", en Ponce Herrero, G. (ed.), La conquista cristiana del valle del Vinalopó. Territorio y fortalezas, Alicante, Publicaciones de la Universidad de Alicante, 2016, pp. 351-376.

Simón García, José Luis y Hernández Carrión, Emiliano, "Trashumancia y arquitectura de piedra en seco en Albacete", Zahora, 57 (2013), pp. 67-89.

Toubert, Pierre, "Le moment carolingien (VIIIè-Xè siècle)", Histoire de la famille, París, Armand Colin, 1986, pp. 333-359.

Trillo San José, Carmen, Agua, tierra y hombres en al-Andalus, Granada, Grupo de Investigación “Toponimia, Historia y Arqueología del Reino de Granada”, 2004.

Al-'Uḍrī, Ahmad b. 'Umar, Tarșī': Nuṣūṣ 'an al-Andalus min kitāb Tarṣī' alajbār, ed. 'A. 'A al-Ahwānī, Madrid, Instituto Egipcio de Estudios Islámicos, 1965.

Watson, Andrew M., Agricultural Innovation in the Early Islamic World, Cambridge, Cambridge University Press, 1983.

Recibido: $12 / 07 / 2016$

Aceptado: 20/12/2017 